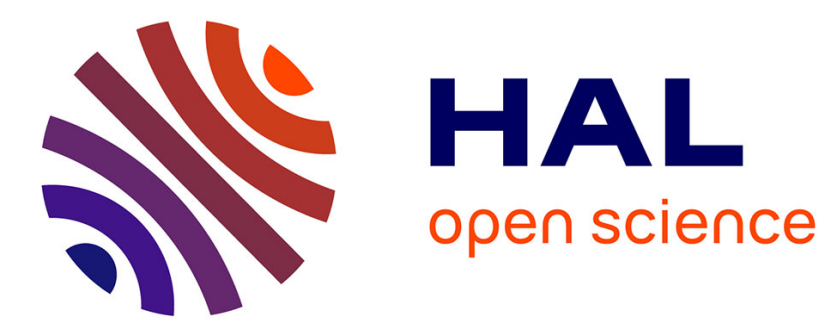

\title{
Neuroplasticity in the maternal hippocampus: Relation to cognition and effects of repeated stress
}

\author{
Jodi L. Pawluski, Kelly Lambert, Craig H Kinsley
}

\section{To cite this version:}

Jodi L. Pawluski, Kelly Lambert, Craig H Kinsley. Neuroplasticity in the maternal hippocampus: Relation to cognition and effects of repeated stress. Hormones and Behavior, 2016, 77, pp.86-97. 10.1016/j.yhbeh.2015.06.004 . hal-01169791

HAL Id: hal-01169791

https://hal-univ-rennes1.archives-ouvertes.fr/hal-01169791

Submitted on 22 Sep 2015

HAL is a multi-disciplinary open access archive for the deposit and dissemination of scientific research documents, whether they are published or not. The documents may come from teaching and research institutions in France or abroad, or from public or private research centers.
L'archive ouverte pluridisciplinaire HAL, est destinée au dépôt et à la diffusion de documents scientifiques de niveau recherche, publiés ou non, émanant des établissements d'enseignement et de recherche français ou étrangers, des laboratoires publics ou privés. 
NEUROPLASTICITY IN THE MATERNAL HIPPOCAMPUS: RELATION TO COGNITION AND EFFECTS OF REPEATED STRESS

Jodi L. Pawluski*1, Kelly G. Lambert*2 ${ }^{2}$, Craig H. Kinsley*³

*All authors contributed equally

${ }^{1}$ University of Rennes 1, IRSET-INSERM U1085, Campus Beaulieu, Rennes Cedex, FRANCE. Email address : j.pawluski@gmail.com

${ }^{2}$ Department of Psychology, Randolph-Macon College, Ashland, Virginia 23005, USA. Email address: klambert@rmc.edu

${ }^{3}$ Department of Psychology, Center for Neuroscience, University of Richmond, Richmond, VA 23173, USA. Email address: ckinsley@richmond.edu.

Corresponding author: Jodi L. Pawluski, PhD,

University of Rennes 1,

IRSET-INSERM U1085,

Campus Beaulieu

Bat 13, Room 135/2

35042 Rennes Cedex

FRANCE

Phone: +33(0)2 23.23.41.90

Email address: j.pawluski@gmail.com 


\begin{abstract}
It is becoming clear that the female brain has an inherent plasticity that is expressed during reproduction. The changes that occur benefit the offspring, which in turn secures the survival of the mother's genetic legacy. Thus, the onset of maternal motivation involves basic mechanisms from genetic expression profiles, to hormone release, to hormone-neuron interactions, all of which fundamentally change the neural architecture - and for a period of time that extends, interestingly, beyond the reproductive life of the female. Although multiple brain areas involved in maternal responses are discussed, this review focuses primarily on plasticity in the maternal hippocampus during pregnancy, the postpartum period and well into aging as it pertains to changes in cognition. In addition, the effects of prolonged and repeated stress on these dynamic responses are considered. The maternal brain is a marvel of directed change, extending into behaviors both obvious (infant-directed) and less obvious (predation, cognition). In sum, the far-reaching effects of reproduction on the female nervous system provide an opportunity to investigate neuroplasticity and behavioral flexibility in a natural mammalian model.
\end{abstract}

Key words: hippocampus, pregnancy, lactation, postpartum, spatial memory, depression, steroid hormones, parental brain 


\section{Introduction}

Pregnancy and motherhood are accompanied by remarkable neurobiological changes. In a healthy mother, fluctuating changes in maternal steroid and peptide hormones during the peripartum period play a significant role in the onset of maternal behaviors, which are necessary for offspring survival (Bartels and Zeki, 2004; Bridges, 2014; Sheeman and Numan, 2002). Upon the arrival of the offspring, trial-and-error learning as a strategy to finetune maternal behavior is too-little, too-late. Although glimpses of maternal responsiveness such as tail carrying, nest building, and altered food preferences may be observed during pregnancy in the rat (Fleming, 2007; Lott and Rosenblatt, 1969; Rosenblatt, 1969, 1980), maternal behavior makes a rather abrupt appearance following parturition. In an almost seamless transition to the postpartum phase, maternal mammals engage in specific responses that are essential for the offspring's survival.

The transformation of an often offspring-aversive virgin animal to an offspring-seeking mother represents one of the most dramatic examples of behavioral flexibility in all of animal behavior. Rosenblatt and Mayer (1995) proposed an approach-avoidance model to explain this transition, suggesting that the motivation to avoid offspring, particularly in rats, is replaced by a competing motivation to approach offspring, post-parturition(Rosenblatt and Mayer, 1995). Interestingly, maternal responsiveness is not exclusive to postpartum rats considering that, even in virgin rats; a period of cohabitation with offspring will stimulate maternal responsiveness after about a week of exposure. Such pup-sensitized females engage in nest building, pup-grooming and crouching over the offspring, even in the absence of lactation (Rosenblatt, 1967). Pup exposure may reduce timidity in the virgins, enabling them to overcome social fears to interact with offspring (Fleming and Luebke, 1981). Maternal rats trained to bar-press to receive offspring, as well as a place preference for offspring-associated over cocaine-associated chambers, provide unequivocal evidence of the rewarding nature of offspring in postpartum females (Lee et al., 1999a; Mattson et al., 2003). An example of this extreme offspring-directed motivation is depicted in Fig. 1, in which a semi-free ranging adult female capuchin monkey was photographed carrying a young raccoon kit. With no males in the facility, the female capuchins were neither pregnant nor lactating, yet they still demonstrated motivation to gain access to offspring, even contra-specific offspring. This misdirected investment of energy in caring for offspring of another species (or conspecific competitors') serves as a vivid reminder of predisposed maternal neural circuitry underlying maternal motivation. This 'maternal circuit' involves such areas of the brain as the medial 
preoptic area, amygdala, prefrontal cortex, and nucleus accumbans (Lee et al., 1999b; Numan, 1988) (Figure 2).

\section{A Tour of the Maternal Brain}

In the case of the manifest changes that accompany the transition from nulliparity to pregnancy through maternity, a maternal brain is both the goal of the endocrine tsunami that accompanies pregnancy, and the culmination of millennia of natural selective processes. That the maternal brain is shaped by what may be termed enriching experiences, and that the responsivity to young remains with the parous female long after her actual production and care of young, suggests that an additional consequence of reproduction may be hitherto subtle cognitive improvements that accrue to the mother.

Previous work has described the maternal milieu as enriching (Kinsley et al., 2012a; Kinsley and Lambert, 2006; Kinsley et al., 1999; Kinsley et al., 2012b; Kinsley et al., 2006). For example, the factors that characterize the processes of pregnancy, production of young, and, critically, the flow of sensory information from the young back to the mother are rich, prolonged and significant (Fleming et al., 2002; Fleming et al., 1999). The cues from the offspring were believed to be more of a signaling device, a way to inform the mother that it was time to feed, or warm or retrieve the offspring. The cues certainly do this, but, as Kinsley et al (2012) have argued, that is but the beginning. Rosenblatt pioneered the notion, with his classic 1967 paper, of pup stimuli alone - in the absence of pregnancy hormones that cues from offspring could render a female rat maternally responsive merely with repeated exposure to the pup cues. Such sensitization or concaveation phenomena were sufficient to elicit maternal care from adult females (Cohen and Bridges, 1981). Such an effect likely involves mechanisms such as those reported by Engert and Bonhoeffer (1999), which involves the transduction of significant amounts of sensation into synaptic/neuronal remodeling via neuronal activation (Engert and Bonhoeffer, 1999). Therefore the amount of sensory information provided by the offspring - the sights, smells, sounds, tastes, somatosensory and suckling stimuli - must be significant and targeted. On the one hand, it helps to inform the mother as to the state of the offspring, requiring the proper response to the stimulus (a specific cry is met with a specific behavior; a particular odor with the proper amount of licking). On the other, the mother's brain is responding to these complex sensory stimuli by becoming structurally and functionally more complex. 
The medial preoptic area (mPOA) has been shown to regulate maternal motivation in a number of mammalian species (Levy, 2008; Numan et al., 2006; Perrin et al., 2007). For example, bar-pressing for offspring is diminished in rats with lesions in the mPOA, whereas stimulation here promotes pup-preferences in maternal females (Lee et al., 1999a; Morgan et al., 1999). Additionally, c-Fos immunoreactive cells are increased in both the mPOA and ventral bed nucleus of the stria terminalis (vBNST), when exposed to a chamber associated with pup cues (Pereira et al., 2008). Both sites are targeted by pregnancy hormones (Numan and Stolzenberg, 2008). Thus, research supports the critical role of mPOA/vBST neurons in the production of maternal behavior (Numan, 2007; Numan and Stolzenberg, 2008). The activated neurons in this area (as determined by Fos expression) project to the ventral tegmentum (VTA) and nucleus accumbens (NAc/NAs) (Numan and Numan, 1997; Stack et al., 2002). During the active phase of maternal behavior in rats, which involves responses such as pup retrieval, there is evidence of dorsal striatum activation as well (Henschen et al., 2013). In turn, the amygdala plays a role in the diminishing pup-avoidance response following parturition. Rats with corticomedial nuclear amygdala (CMA) lesions displayed more rapid maternal behavior compared to females with basolateral (BLA) lesions. The data suggest that decreased amygdala activation, which normally mediates fearfulness and avoidance behavior, may play a role in the reduced neophobic responses to offspring observed in maternal rats (Fleming et al., 1980; LeDoux, 1996). Thus, research has identified several brain areas associated with the transition from pup-avoidance to pup-directed behaviors characteristic of the maternal female. The mPOA, BNST, VTA and NAc/s are associated with the attraction side of the equation, whereas the amygdala controls pup avoidance, prior to parturition in rats. These data support the approach-avoidance model first proposed by Rosenblatt and colleagues (Numan, 2007; Numan and Insel, 2003; Rosenblatt and Mayer, 1995).

Corroborating evidence for this theoretical framework is also found in paternal behavior in which decreased activation of amygdala cells (via fos-immunoreactive cells) was correlated with increased motivation to approach offspring in the monogamous biparental California deer mouse, compared to the closely related uniparental common deer mouse (Lambert et al., 2011); additionally, fos-immunoreactivity, as well as oxytocinimmunoreactive fibers, were observed in the PVN in paternal mice (Lambert et al., 2011; Lambert et al., 2013). Focusing on juvenile male rats, the mPOA appears to play a role in pup-sensitized parental behavior (Rosenblatt et al., 1996). Thus, several diverse animal 
models, including male parenting models, support a central cluster of brain areas underlying specific aspects of the maternal motivation continuum (see Figure 2 and 3 for a list of brain areas involved in maternal behavior).

Given the consistency of brain areas involved in maternal motivation in animal/mammalian models, neuroimaging studies have been conducted to determine the degree to which these functional circuits have been conserved in human mothers. When mothers are exposed to standard baby cries, functional magnetic resonance imaging (fMRI) scans reveal increased activity in the anterior cingulate and medial prefrontal cortex (Lorberbaum et al., 1999). Interestingly, damage to the anterior cingulate disrupts the pattern of maternal responsiveness in rodents (Slotnick, 1967). The cingulate was also proposed as part of a thalamocingulate theory of maternal behavior (MacLean, 1990). In a subsequent study focusing on breast-feeding human mothers, the same research design indicated that brain areas involved in rodent maternal behavior were also activated in humans, including the VTA, hypothalamus, and striatum (Lorberbaum et al., 2002).

Exposing mothers to visual, as opposed to auditory, stimuli (i.e., pictures of their children) yielded increased activity in the insula, anterior cingulate, striatum and periaqueductal gray. With decreased activity reported in areas of the brain involved in negative emotions (viz., the amygdala), these data also support a transition from an avoidance to attraction phase, or a push-pull mechanism (Bartels and Zeki, 2004). Another study focusing on the visual cues of infant faces with varying emotional expressions indicated that, when mothers observed their own infants' face, the ventral striatum, thalamus and NA (viz., reward areas), and brain areas associated with oxytocin projections (e.g, BNST; (Strathearn, 2002; Swain, 2008) displayed increased activation. New mothers (two-four weeks following delivery) listening to their own baby crying had more activity in the insula, cingulate, midbrain and striatum compared to a control condition of standard baby cries (Swain et al., 2003).

Thus, investigations of multiple species using multiple methodological approaches have identified a maternal circuit in the maternal brain that appears to have been conserved across mammals (Swain, 2011). These disparate brain areas converge to produce the streamlined maternal responses directed toward the offspring, sometimes referred to as "on the nest" responses (Lambert, 2012). Yet, the peripartum period is also a time when women experience modifications to other behaviors, such as cognition and emotion, which are also 
associated with plasticity in the maternal brain. For example, up to $75 \%$ of women report peripartum changes in cognition (Crawley et al., 2003) and up to $20 \%$ of pregnant women suffer from a mental illness (Bennett et al., 2004). Both cognition and mental health rely, in part, on the hippocampus. Therefore, it is not surprising that changes in hippocampal plasticity are evident with the transition to motherhood.

Beyond the diverse brain areas implicated in maternal behavior, this review focuses on plasticity in the maternal brain as it relates to changes in cognition and emotion throughout pregnancy, the postpartum period and aging. The primary emphasis will be on plasticity in the hippocampus, as this brain area is arguably one of the most plastic regions in the adult brain. The hippocampus is one of two areas of the brain that exhibit a high degree of neurogenesis throughout the lifespan, the other being the subventricular zone, and it is likewise very sensitive to steroid hormones which can alter hippocampal neurogenesis and result in dendritic and synaptic remodeling. The hippocampus is divided into three main areas, the cornu ammonis (CA) 1, CA3 and dentate gyrus (Amaral and Witter, 1995). The subgranular zone of the dentate gyrus is where a high rate of neurogenesis takes place across the lifespan. Furthermore, neurogenesis is comprised of 4 stages: cell proliferation, migration, differentiation and cell survival (Galea et al., 2013). All of these can be affected by a variety of different endogenous and exogenous factors. Apart from these modifications, plasticity in the maternal brain involves changes on many levels from gene expression, receptor densities, neuron production and morphology, and area volumes [for further review see (Galea et al., 2014; Hillerer et al., 2014a; Leuner et al., 2010; Levy et al., 2011)]. Thus, the maternal brain is a dynamic system greatly influenced by reproduction.

\section{Neurobiological Flexibility and the Maternal Brain}

The neurobiological changes that accompany the onset of motherhood provide evidence of the flexibility of the mammalian brain to meet the demands of the offspring in real time. This neurobiological flexibility differs from the more general term neuroplasticity in the sense that the observed maternal-changes are thought to be adaptive modifications to assure the wellbeing of offspring as opposed to less specific functional modifications related to factors such as aging, enrichment or disease. As indicated in this section, preliminary research suggests that these maternal-induced changes may be either transient or long-lasting. Research investigating the specific functional trajectories for new and existing neural cells will 
certainly inform questions about neuroplasticity and maternal behavior (Levy et al., 2011; Vivar and van Praag, 2013). Thus, more research is necessary before more definitive statements can be made about the enduring nature of maternal-induced neurobiological modifications.

\section{a. Reproduction-induced cognitive changes}

It has been estimated that up to $75 \%$ of women report short-term memory loss, forgetfulness, disorientation, lack of concentration, or reading difficulties during the peripartum period which improve within one year of birth (Buckwalter et al., 2001). Anecdotal reports of this "baby brain", "porridge brain", or "maternal amnesia" are substantiated, in part, with research findings of decreased verbal recall and prospective memory in women during late pregnancy and the early postpartum period, particularly when everyday life memory tests are used outside the laboratory (for further discussion see (Christensen et al., 2010; Crawley et al., 2003; Cuttler et al., 2011; de Groot et al., 2006; Parsons et al., 2004; Poser et al., 1986). Rodent research has also shown that hippocampaldependent spatial memory is impaired in the rat dam during late gestation and early postpartum period (Darnaudery et al., 2007; Galea et al., 2000).

The described memory deficits during late pregnancy and the early postpartum period may be due to an interplay between hormones and neuroplasticity that prepare the mother for the arrival and care of her young; thus a 'trade-off' may occur with other cognitive abilities, such as learning to care for her young, being enhanced during this time. The decrease in spatial memory during the peripartum in rodents extends this idea and is likely due to the fact that there is an advantage for the late pregnant female and very new mother to stay close to the nest site.

Although there has been no research on memory function in young human mothers two years after giving birth, in rodents memory is consistently enhanced during the late postpartum period and after weaning (Gatewood et al., 2005; Kinsley et al., 1999; Love et al., 2005; Pawluski and Galea, 2008; Pawluski et al., 2006), suggesting an enduring effect of reproduction on cognition. This enhancement in cognition during the postpartum period and after weaning is perhaps not surprising as the new mother needs to perform a host of tasks apart from offspring-directed care to ensure that offspring survive. For example, the maternal rat, as the sole caretaker for often a dozen offspring, needs to be an efficient forager in order to maximize her harvesting yield without expending unnecessary energy required for 
lactation; additionally, maternal rats need to minimize the time spent off the nest in order to protect vulnerable offspring (especially if they are not in a communal nesting context).

Based on performance in spatial learning tasks, foraging ability was initially observed to be enhanced in postpartum rats still lactating or with recent maternal experience. Furthermore, offspring-sensitized females also exhibited increased foraging efficiency over nulliparous females (Kinsley et al., 1999). When offspring were removed from female rats immediately following parturition, they didn't exhibit enhanced foraging responses, indicating the importance of pup stimuli in the facilitation of altered ancillary responses (Lambert et al., 2005). Transitioning from foraging to hunting, a task that involves a moving target, maternal females have also exhibited superior performance. Specifically, when females with previous reproductive experience were exposed to live crickets, lactating females had shorter latencies to capture the crickets than non-lactating females, even when they were food deprived for longer durations (Kinsley et al., 2014). Finally, even when the hippocampus is compromised via the delivery of kainic acid (causing subsequent hippocampal damage), rats with maternal experience exhibited no evidence of spatial and cognitive deficits, suggesting that recovery from neural damage is more efficient in the maternal hippocampus (Franssen et al., 2012).

Extending our theorizing to another interesting animal model, foraging ability was recently evaluated in captive monogamous, biparental owl monkeys. When these monkeys had parental experience, both males and females exhibited more efficient foraging patterns when presented with a foraging tree outfitted with small rubber coin purses containing either high or low value (caloric) food rewards. That is, they were better at recalling which purse held the higher-value food. Too, reproductively experienced owl monkeys had higher DHEA/cortisol ratios (based on urinary metabolites), consistent with enhanced emotional resilience (Bardi et al., 2014; Morgan et al., 2009; Wemm et al., 2010).

Modifications to stress responsiveness, changes in hormone profiles and foraging activity are intricately linked to plasticity in the hippocampus as this area of the brain plays an important role in stress regulation, is highly sensitive to steroid hormones, and mediates spatial memory performance (Galea et al., 2013). Changes in stress responsivity and levels of anxiety may alter levels of neuroplasticity to coincide with reproduction-induced neurobiological flexibility.

\section{b. Reproduction-induced neuroplasticity: A mechanism for cognitive changes}


As mentioned above, the peripartum period represents one of the most plastic developmental phases in a mammal's life, on a par with other hormonal-developmental epochs. Consequently, this dynamic developmental phase presents a valuable context to gain a more thorough understanding of the mechanisms and functions of neuroplasticity (Hillerer et al., 2014a). During each phase of the reproductive life; pregnancy, postpartum and postlactation evidence shows a significant effect on plasticity in the maternal brain and these changes in plasticity in the hippocampus, as well as other regions of the maternal brain, likely play a prominent role in cognitive flexibility in the mother. Below is a summary of recent work on hippocampal plasticity during pregnancy, the postpartum and beyond.

\section{i. Pregnancy and the hippocampus}

Although there is little research on plasticity in the maternal brain during pregnancy itself, this is a significant period during reproduction that can alter the peripartum transition to motherhood. In addition, there are often significant differences between antepartum and postpartum behaviors. In women, total brain size decreases during pregnancy and returns to preconception levels by six months postpartum (Oatridge et al., 2002). Interestingly ventricle size shows a concomitant increase during pregnancy, with a decrease during the postpartum period, demonstrating an overall decrease in brain volume in pregnant women (Oatridge et al., 2002). Recent work in rodents has reported a reduction of brain size during early lactation (Hillerer et al., 2014b) and a reduction in hippocampal volume in pregnant rats (Galea et al., 2000).

Some of the first work on hippocampal neurogenesis during pregnancy was carried out in the meadow vole (Table 1). This work showed that pregnant wild meadow voles captured during the breeding season have decreased levels of hippocampal cell proliferation compared to non-pregnant female meadow voles captured during the non-breeding season (Galea and McEwen, 1999). Given the significant changes in hormone levels between breeding and nonbreeding seasons in female meadow voles (as well as during pregnancy in many species), these authors investigated circulating estradiol and corticosterone levels in these wild-caught meadow voles and found a significant negative correlation between circulating levels of estradiol and corticosterone and hippocampal cell proliferation. Thus, this work showed that decreases in hippocampal cell proliferation are associated with increases in circulating levels of corticosterone and estradiol in pregnant meadow voles (Galea and McEwen, 1999). Work in the pregnant rat has shown that expression of the polysialylated form of the neural cell 
adhesion molecule (PSA-NCAM), which plays a well-documented role in migration (Gascon et al., 2007; Seki and Arai, 1993), is increased during late gestation in pregnant female rats compared to virgin female rats (Banasr et al., 2001). These authors also reported no significant difference in cell proliferation in late pregnant females compared to cycling females, and subsequent research has found little evidence that pregnancy is associated with changes in cell proliferation in the hippocampus of the mother during early gestation (GD1 and GD7) (Pawluski et al., 2010; Shingo et al., 2003) or cell proliferation and new cell survival during late gestation (GD21) (Furuta and Bridges, 2005; Pawluski et al., 2010; Pawluski et al., 2011; Shingo et al., 2003). Others have reported a reduction in cell survival during the second week of gestation in mice, with a return to prepregnancy levels during the postpartum period (Rolls et al., 2008).

The initial study investigating hippocampal neurogenesis during pregnancy in wildcaught meadow voles showed a significant association between estradiol and corticosterone levels and levels of hippocampal cell proliferation (Galea and McEwen, 1999). However, subsequent work in rats has not reported an association between hippocampal cell proliferation or neurogenesis and circulating levels of estradiol or corticosterone (Pawluski et al., 2010; Pawluski et al., 2011). Much more work is needed before we can fully determine the role of increased circulating levels of steroid hormones during gestation and hippocampal neurogenesis in the maternal brain.

It is perhaps surprising that the hormones of pregnancy have little effect on hippocampal neurogenesis in the female given the significant effects of estradiol on plasticity in the female hippocampus (Galea et al., 2013; McEwen, 2002; Pawluski et al., 2009); recent research has demonstrated, however, that steroid hormones play a role in dendritic remodeling in the maternal hippocampus. Spine density in the apical CA1 region of the hippocampus is increased during late pregnancy compared to virgin females (Kinsley et al., 2006) and these effects appear to be due to increased estradiol and progesterone levels at this time (Kinsley et al., 2006). Others have also shown that at birth, parturient females have decreased spine density in the apical region of CA1 pyramidal cells (Frankfurt et al., 2011). These data further support the role of estradiol on CA1 synaptic plasticity with high levels of estradiol during late gestation being associated with increased spine density, and low levels of estradiol after birth being associated with decreased spine density. Late pregnancy is also associated with a significant reduction in the complexity of CA3, but not CA1, pyramidal neurons, compared to 
age-matched virgin females (Pawluski et al., 2012b). For a summary of all effects see Table 1.

It should also be noted that the subventricular zone, a highly neurogenic zone during adulthood with proliferating cells migrating to the olfactory bulb, exhibits a significant upregulation of neurogenesis in the rodent maternal brain (Larsen and Grattan, 2012; Larsen et al., 2008; Shingo et al., 2003). Given the significance of olfaction in maternal care of offspring, an increase in neurogenesis in the SVZ is perhaps not surprising and it has been suggested that increases in subventricular zone neurogenesis during pregnancy plays an important role in maternal postpartum motivation and care of young (Larsen and Grattan, 2012).

\section{ii. Postpartum and the hippocampus}

In addition to the studies conducted during pregnancy, a multitude of studies have assessed levels of neurogenesis and other neuroplasticity variables in the peripartum and lactation phases of the maternal experience in many brain regions (prefrontal cortex, mPOA, amygdala, olfactory bulb), however much of this more recent work has centred on the plasticity in the hippocampus. Tomizawa et al. (2003) were the first to show that electrophysiology in the hippocampus is altered with motherhood. Specifically, it was reported that multiparous mice exhibit increased long-lasting long term potentiation (LTP) along the Schaffer collaterals during the early postpartum period (day 3) compared to nulliparous mice (Tomizawa et al., 2003). It has also been consistently demonstrated in the rat and sheep that cell proliferation in the hippocampus of the mother during the early postpartum period is decreased compared to age-matched virgin females (Brus et al., 2010; Darnaudery et al., 2007; Hillerer et al., 2014b; Leuner et al., 2007; Pawluski and Galea, 2007)(Table 2) and there is a decrease in immature neurons at weaning (Workman et al., in press). This decrease appears to be related in part to reproductive experience, circulating adrenal steroids, and is associated with learning and memory in the mother (Darnaudery et al., 2007; Leuner et al., 2007; Pawluski and Galea, 2007). For example, Darnaudery et al. (2007) described a decrease in cell proliferation in lactating female rats on postpartum day 1 (PD1) with no difference between lactating and virgin females in BrdU-labeled cells during mid lactation ( 2 weeks later). They also found that during the early postpartum period (PD14) maternal rats had poorer learning and memory coincident with decreased cell proliferation in the hippocampus. Reproductive experience and pup exposure also influence cell survival 
in the hippocampus of the mother during the postpartum period (Pawluski and Galea, 2007). Pawluski and Galea (2007) show that primiparous rats had significantly fewer new surviving cells during the postpartum period, regardless of pup-exposure and lactation, than either nulliparous or multiparous rats. Interestingly, they found that multiparous females had a greater proportion of surviving new neurons compared to nulliparous and primiparous females across the postpartum period. Recent research in biparental California mice expand this finding and show that both mothers and fathers have a decrease in surviving new hippocampal neurons during the postpartum period (Glasper et al., 2011), demonstrating a significant impact of reproductive experience on both maternal and paternal hippocampal plasticity.

Research also demonstrates the enriching properties of pup-exposure on the hippocampus of virgin animals. Previous work has shown that nulliparous females exposed to pups have increased levels of neurogenesis in the hippocampus, via both cell proliferation and cell survival, compared to lactating dams (primiparous and multiparous) and nulliparous females not exposed to pups (Pawluski and Galea, 2007). This effect is also evident in virgin prairie voles, a biparental species, where both virgin male and virgin female voles exposed to pups, regardless of whether or not they acted parentally towards the pups, had increased hippocampal cell proliferation (Ruscio et al., 2008). Interestingly, the voles that were nonparental had significantly increased levels of cell proliferation compared to the voles that were parental (Ruscio et al., 2008).

Although investigated to a lesser extent, spine remodeling is also evident in the maternal hippocampus during lactation. Kinsley et al (2006) report that rat dams have increased spine density in the CA1 apical region of the hippocampus during early lactation (Kinsley et al., 2006) and others have shown that this effect persists into the late postpartum period (Leuner and Gould, 2010) but not after weaning (Pawluski and Galea, 2006).

The effects of motherhood on the maternal hippocampus persist after the cessation of lactation. Increased hippocampal LTP with motherhood exists two weeks after weaning and well into aging (Lemaire et al., 2006). In addition, primiparous rats, at weaning, exhibit decreased dendritic complexity in both the CA1 and CA3 pyramidal neurons compared to nulliparous as well as multiparous rats (Pawluski and Galea, 2006). In this same study, multiparous rats had enhanced spine density in the CA1 region of the hippocampus, and spine density correlated with number of male pups in a litter (Pawluski and Galea, 2006). However, changes in the morphology of CA1 pyramidal neurons with parity are not evident in aged 
rats, suggesting that these changes are reversible (Love et al., 2005). See Table 2 for summary.

Motherhood has also been shown to have lasting effects on the response of hippocampal progenitor cells to estrogens, with different estrogens significantly upregulating cell proliferation in the hippocampus in middle-aged multiparous females but not of middleaged virgins (Barha and Galea, 2011). Furthermore, Gatewood et al (2005) have shown that reproductively experienced females show a reduction in amyloid precursor protein (APP), a marker of neurodegeneration, with parous rats generally having fewer hippocampal deposits of the deleterious substance (Gatewood et al., 2005). Overall, this suggests modulation of the maternal hippocampus at the cellular level and demonstrates the lasting effect of previous reproductive experience on the aging brain

\section{c. Reproduction-induced remodeling of the aged brain}

Aging, especially the aging brain, is multiply determined. There are, however, interesting interactions between reproduction and the aging brain [see (Kinsley et al., 2012a)]. There are links between the enriching events of reproductive experience and cognition, with reproductive experience having long-lasting and widespread effects on the maternal brain and behavior (Kinsley and Lambert, 2006). To some regard, the enduring effects of maternal experience may be referred to as neuroprotective, and, therefore, positive.

\section{i. Enduring effects of maternal experience}

Gatewood et al. (2005) were perhaps the first to examine the long-lasting effects of reproductive experience on memory, out to the latter stages of the female rat's life (paralleling a human in her mid-80s). They compared the spatial learning and memory of age-matched nulliparous, primiparous, and multiparous two years post-reproduction testing at six, twelve, eighteen, and twenty-four months of age on a task, involving the memory of the location of a baited food well in the dry land maze [DLM; a waterless mimic of the Morris water maze; (Kesner and Dakis, 1995)]. The data show a significant preservation of spatial memory in reproductively experienced females. A complementary experiment extended these original data. Beginning at 12, and continuing until 24 months of age, the animals underwent additional testing (utilizing a so-called "reversal task"), which required that they "forget" the original contingency, and learn a new one (a novel location for the food reward such as switching the baited food well from NW to SE), thereby measuring the flexibility of their 
learning. At each age, and for both the primary and reversal tasks, the multiparous females performed significantly better (remembering the baited location significantly faster) than both the nulliparous and primiparous females. On the other hand, the primiparous females learned the mazes significantly faster than the nulliparous females at 12, 18, and 24 months (in the primary task) and at 12 and 24 months (in the reversal task). It is important to acknowledge that this is long after maternal-infant interactions. The earlier reproductive experience appears to linger, regulating the animals' behavior late in life, and strongly suggesting that reproductive experience may contribute to late-in-life hippocampal integrity and function.

Extending the work of Gatewood et al (2005), Love et al. (2006) demonstrated a significant effect on a competition task designed to assess the extent to which reproductive experience might regulate post-reproduction competition. Age- and weight-matched nulliparous, primiparous and multiparous female rats were trained to locate the placement of a food reward in a large ( $5 \mathrm{ft}$ diameter) dry land maze. Once the animals reached criterion, they were tested in triads and observed for which animal out of the trio obtained the food reward before the others. Out of $100 \%$, the relative proportions of food acquisition clearly show that parous animals, particularly multiparous females (at $60 \%$ of the time), were significantly better, faster, at obtaining the food under competitive conditions, with primiparous females next (at 33\%), followed by nulliparous females (at 7\%).

Others have also shown an enduring effect of multiparity on recognition memory in rats (Macbeth et al., 2008). These data are intriguing. They suggest that parous animals have a competitive advantage relative to virgins, and that the effects may be cumulative, increasing with additional reproductive experience.

Another prediction that arises from the latter data is the extent to which the relative attractiveness of the female may change with reproductive experience. Imagine Nature or natural selection as a bettor faced with multiple choices on which to place a bet. On the one hand, the personified gambler has a fertile, hypothetically fecund, virgin female with all the potential for reproduction. On the other is a female that has realized that potential. It is the difference between what could happen, and what has happened, probability versus reality. Therefore, on which female would the bettor likely place his/her bet? The promise of reproduction, or the achievement of it? That is, if given the choice, would males prefer females with demonstrated reproductive experience? To test this idea, Chan and Kinsley (unpublished observations) exposed male rats to soiled bedding obtained from age-matched 
nulliparous, primiparous and multiparous females. The data suggest that the males were more attracted to the odors of parous females. In other words, the males may find the odors of parous females more interesting and compelling, than the odors from nulliparous females. There are two interesting conclusions here: one, some feature of the soiled bedding, likely pheromonal, contains one or more voluble compounds that possess signaling properties that the male finds attractive. Second, that the male is attracted to the mother's odors indicates an interesting evolutionarily-forged relationship that highlights an enhanced female value associated with reproduction. It is axiomatic that males prefer younger females because of the increased likelihood of prolonged fertility (Buss, 2003; Gangestad et al., 1994; Rhodes, 2006). Perhaps complementing such attractions are more basic considerations governed by a demonstrated ability to reproduce. Again, it is the difference between promise and realization. And it suggests effects that are supra-reproductive, arising from but independent of the actual production of young.

What about the effect of neuroplasticity in the aging mother? As discussed above, the events of pregnancy and production of young may be considered enriching, with a complex set of stimuli bathing the brain that results in persistent, if not permanent, outcomes. As noted, reproductive experience has persistent enhancing effects on spatial learning and memory. Not surprisingly the likely neural regulators - or, at least, correlates - of the memory improvements in parous females have been investigated in the aged parous rats (24months of age)(Gatewood et al., 2005; Love et al., 2005; Macbeth et al., 2008). The parous rats generally had fewer hippocampal deposits of the deleterious substance, amyloid precursor protein (APP), compared to nulliparous females, and the parous animals' APP levels were negatively correlated with performance in both the main and reversal tasks (i.e., more APP $=$ poorer maze performance)(Gatewood et al., 2005). In line with this, aged multiparous rats also exhibit increased levels of brain-derived neurotrophic factor (Macbeth et al., 2008) and reproductive experience has lasting effects on hippocampal cell proliferation in response to estrogens (Barha and Galea, 2011). These effects are surprising, given that the only manipulation these females received was reproductive experience - an amalgam of natural experiences. The events surrounding reproductive experience, therefore, (e.g., mating stimuli, elevations in pregnancy hormones such as estrogen, progesterone, oxytocin, etc., lactational prolactin, etc., cues and/or stimulation from the young, etc.), may accrue, producing a female brain that is both flexible and, perhaps, healthier later in life (Perls et al., 1997). 
The possibility that offspring act as an enriched environment with enduring effects on the maternal brain (see (Kinsley et al., 1999); (Vallee et al., 2001) [which discusses pregnancy-related steroids and, thus, subsequent pup cues]) is suggestive. However, enriching environments have positive effects on Alzheimer's disease pathology (Bennett et al., 2003). It is possible, therefore, that earlier-in-life experiences (including reproductive) may prevent some negative subset of aging symptomology. Thus, following on the above observation of reduced hippocampal deposits of APP, Kinsley and colleagues have begun to test these hypotheses. This work examined transgenic mice that over-express the APP protein (Jackson Lab's B6.Cg-Tg[PDGFB-APP]5Lms/J; Kinsley \& Brown, unpublished observations). Half of these mice were mated and allowed thereafter to remain with their offspring through weaning. Ten days following weaning, the animals underwent behavioral training, on a spatial memory task. Though preliminary, the data point to a small cause and a big effect: the primiparous transgenic females significantly out-performed the nulliparous transgenic females in a probe task, which involved the cumulative time spent near the previously baited food well. The behavioral improvements occurred at a time ( 170d) when the age-progression of the APP effects otherwise begin to exert themselves, negatively, in this animal model of age-related neurodegeneration. In other words, reproductive experience reduced the accumulation of APP, or shielded, in part, the females from some of the deleterious effects of the APP accumulation.

Using another mouse model for Alzheimer's Disease, however, the APP23 mouse, research has shown the opposite - that reproductive experience may decrease cognitive performance and increase plaques in the hippocampus of the aged female mouse (Cui et al., 2014). Clearly more work is needed in this area to resolve these ambiguities.

Interestingly the enduring effects of reproductive experience on memory and cognition do not appear to extend to humans. In women, parity is associated with an earlier age of onset for dementia and an increased risk to develop Alzheimer's Disease (Colucci et al., 2006; Ptok et al., 2002; Sobow and Kloszewska, 2004). The interaction between reproductive experience and genotype appear to contribute to the enduring effects of reproduction in humans.

\section{ii. Evolutionary implications of the enduring effects of reproductive experience}

Again, this phenomenon raises an interesting question, and one with evolutionary implications: why? That is, why should the residue of reproductive experience linger after 
the offspring have been weaned? The maternal rodent appears to retain the enhanced learning and memory abilities that they developed around the experiences of reproduction when, it can be argued, the benefits are most needed - taking care of young, providing food and water, protecting nest and its contents, etc. Based on assessments of various cognitive abilities, parous female rats function more efficiently well out to the latter stages of their lives at a time, however, when their offspring are no longer present or requiring the intensive care required earlier in their lives. It is curious, then, what this "value added" set of qualities means. In other words, why should these effects persist in the female rat after she has already reproduced? Is it possible that previous reproductive experience translates into modifications related to enhanced adaptation?

Although persistent cognitive benefits are not evident in the human mother, there is no doubt that reproductive experience can leave a 'mark' on the maternal brain. Where might the long-term effects of reproductive experience be transpiring? As discussed above, significant effects of reproductive experience and associated hormones on neuronal structure have been reported in areas of the maternal circuit as well as the hippocampus. For example, Keyser et al (2001) demonstrated yet another interesting feature of the female brain: the ability of neurons in the mPOA, which is heavily involved in the display of maternal behavior, to modify their shapes under hormonal stimulation (Keyser-Marcus et al., 2001). Such anatomical alteration is likely in preparation for the demands of parental care during the so-called postpartum initiation phase (first few days postpartum), and is then maintained by pup cues during the maintenance phase. Perhaps, in light of the work demonstrating the exquisite regulation of neuronal structure via neuronal stimulation (in hippocampus, however: [(Engert and Bonhoeffer, 1999)]), neurons may translate sensory stimulation (viz., pup cues) into anatomical change. These effects may involve oxytocin regulation of MAP kinases, as suggested by Tomizawa et al. (2003), translating activity into neuronal plasticity and enhancing spatial cognition. Either way, the data suggest that the hormones of pregnancy, and/or offspring stimulation, are capable of altering the shape and complexity of mPOA neurons, neurons in the hippocampus as well as in other areas of the maternal brain (Kinsley and Lambert, 2006; Kinsley et al., 2006). It is clear that the maternal brain is remarkably flexible, and that this plasticity contributes to a collection of behaviors that ensure the care and protection of the female's investment. The sum total of this activity is maternal investment in offspring and, therefore, a greater probability of successful reproduction. In 
return, perhaps the female gains a bit of compensation through age-related enhancements brought about by those same reproductive events.

\section{d. The maternal brain as an optimal neuroplasticity model}

Although neurogenesis is a conserved evolutionary process in animals, hippocampal neurogenesis may be a more recent evolutionary trait that emerged as the dentate gyrus evolved. More specifically, having a dentate gyrus that could temporally adapt and incorporate new neurons into existing circuitry may have been an important mechanism for optimizing cognitive flexibility and its applications (Kempermann, 2012). As described by Paul MacLean (1990), maternal behavior is a defining characteristic of mammals; thus, the possession of a brain area that translates experience into neuroanatomical modifications may have facilitated the efficient and timely emergence of a host of sensitive maternal responses. For example, each day a maternal mammal's offspring produce slightly modified sensory stimuli (e.g., altered vocalizations, activity, suckling intensity) and it is critical for the maternal brain to be sensitized to and monitor these fast-paced developmental changes; time stands still for neither mother nor young. Although the dentate gyrus evolved prior to mammals (as seen in birds, reptiles and fish), the mammalian form of the dentate gyrus is unique, with hippocampus growth increasing with the evolutionary introduction of the corpus callosum (Humphrey, 1967; Kappers, 1936). Hence, it is possible that the hallmark of mammalian evolution, maternal behavior, required a unique neural network to ensure its smooth functioning.

As mammals navigate novel environments, looking for ways to efficiently exploit resources, it is important to maintain past memories that may be relevant for the new habitats, as well as to incorporate new memories as new contexts are encountered (e.g., the presence of helpless offspring). This ability to utilize both past memories while new memories are being forged is likely possible due to the plastic functions of the dentate gyrus. The cognitive flexibility required to respond to new and dynamic situations could be facilitated by pattern separation, a function enabling the animal to distinguish between two stimuli by marking, or time-stamping, the new information that has been associated with the dentate gyrus (Aimone et al., 2010; Kempermann, 2012). Thus, Kempermann proposed the innovative theory that adult neurogenesis may have been reengineered from a basic fundamental evolutionary neural mechanism to a refined mechanism of brain plasticity and behavioral flexibility (Kempermann, 2012). Following this line of thinking, hippocampal neuroplasticity may be 
more closely aligned with the detection of contextual patterns, more so than just spatial ability (Garthe and Kempermann, 2013).

If the emergence of a new and improved dentate gyrus and hippocampus coincided with the emergence of mammals, it is interesting to consider how the need for sophisticated pattern and contextual differentiation required for the care of offspring may have played a role in the restructuring of dentate gyrus and adult neuroplasticity. Enhanced neuroanatomy translates into enhanced capacity and resultant changes in sensitivity. As the daily maternaloffspring context changes - the offspring mature and develop new behaviors that impinge in ever new ways on the mother's sensory systems, and to which she must adapt - the timedependent changes observed in previous research assessing hippocampal neuroplasticity during the postpartum period may become clear. The interplay, therefore, between the brain's ability to produce new neurons that influence existing neural functions, even in early stages of cellular development, and the brain's ability to adapt in real time to the changing context accompanying motherhood, provides even further evidence of the influential role of maternal behavior in mammalian evolution. In other words, the dentate gyrus may facilitate the creation of neural algorithms that coincide with maternal behavior-induced behavioral flexibility by strengthening existing connections between neurons and efficiently adding new neurons to improve behavioral outcomes.

\section{Prolonged and Repeated Stress Remodel the Maternal Brain}

As described in the previous sections, evidence suggests that reproductive experience alters the female brain in adaptive ways. What might be some of the origins of this effect? Among these enhancements are marked and significant behavioral modifications, due to reported changes in the brains of maternal rats, which include increases in spatial memory, aggression, and exploratory behavior, as well as decreased anxiety and attenuated stress responsiveness. Indeed pregnancy and motherhood are well documented periods when there is a reduction in response to stressors (Douglas et al., 2003; Lonstein, 2005; Neumann et al., 1998; Slattery and Neumann, 2008). Because stress responses have high energy costs, it is optimal for maternal animals' needs to minimize such high metabolic costs during lactation. In line with this, recent work shows that during late pregnancy, females have increased glucocorticoid receptor levels in the hippocampus compared to virgin females, suggesting one potential mechanism by which this hyporesponsive period to stress may be mediated (Pawluski et al., 2015). Further work reports that when postpartum rats were exposed to an 
open field task, maternal animals exhibited fewer behavioral stress responses (e.g., freezes) and less fos-immunoreactivity in the basolateral amygdala and hippocampus CA3 than nonreproductive females (Wartella et al., 2003). Approximately 6 weeks post-weaning and continuing well into aging (22 months), females with reproductive experience exhibited fewer anxiety responses on an elevated plus maze (Byrnes and Bridges, 2006; Love et al., 2005). Furthermore, at 22 months of age, multiparous rats spent significantly more time exploring a novel stimulus (Love et al., 2005). This research suggests that, similar to observed in cognitive tasks, the anxiety response exhibits long-term effects in reproductively experienced rats (Love et al., 2005). Research focused on human mothers has implicated the role of oxytocin in diminished stress responses in postpartum females; with enhanced positive emotions during this time facilitating the affiliative shift in maternal bonding characterized by gazes, vocalizations and affectionate touches directed to infants (Feldman et al., 2007).

Reproduction is also a time when women become vulnerable to the effects of repeated and prolonged stress with $20 \%$ of women showing mental illnesses, such as depression, during pregnancy and the postpartum period (Bennett et al., 2004). Risk factors for developing depression during the perinatal period include a history of depression or anxiety, stressful life events, lacking social support, unplanned pregnancy, and being of lower socioeconomic status (Lancaster et al., 2010; Stewart, 2011). Women suffering from severe stress, depression, or anxiety during gestation can put their infant at risk for poor physical and mental development (Huizink et al., 2003; Oberlander et al., 2009; Talge et al., 2007) including impairments in cognitive abilities, such as language development (2 year old), impulsivity in cognitive tasks (14 year old and 15 year old), lower school marks (6 year old), and increased risk to develop neuropsychiatric disorders such as autism (4 to 12 year old) (Beversdorf et al., 2005; Huizink et al., 2004; Huizink et al., 2003; Laplante et al., 2004; Niederhofer and Reiter, 2004; Van den Bergh et al., 2005; Van den Bergh et al., 2008). In animals models, repeated stress before gestation, during the prenatal period and postpartum can significantly affect offspring development on a number of domains from behavioral performance, physiology and neural plasticity and these effects are dependent on the age and sex of the offspring (Glover et al., 2009; Huang et al., 2010; Maccari and Morley-Fletcher, 2007; Van den Hove et al., 2005; Weinstock, 2007)

A growing body of research is also showing how repeated stress exposure while pregnant can alter neurobehavioral outcomes in the mother by modifying maternal care (Brummelte and Galea, 2010; Hillerer et al., 2011; Smith et al., 2004), and increasing 
depression- and anxiety-related behaviors during the postpartum period (Darnaudery et al., 2004; Leuner et al., 2014; O'Mahony et al., 2006; Smith et al., 2004), thus acting as a model of postpartum depression. Interestingly, repeated stress has limited effects on anxiety-like behavior and depressive-like behavior in the pregnant female (Baker et al., 2008; Pawluski et al., 2015; Pawluski et al., 2011), suggesting differential effects on affective behaviors during pregnancy and lactation.

Stress also affects hippocampal neurogenesis, and alterations in hippocampal neurogenesis play a role in both anxiety- and depressive-like behaviors (Eisch et al., 2008; Wainwright and Galea, 2013). In adult virgin female rats, the effects of stress on hippocampal neurogenesis appear to be dependent on the duration of the stress and the age of the new surviving cells [for review see (Pawluski et al., 2009)]. For example, virgin females subject to repeated stress have increased survival of new cells in the dentate gyrus of the hippocampus a few days after the stress (Westenbroek et al., 2004), but acute stress has no effect on cell proliferation in the hippocampus of the adult female (Falconer and Galea, 2003; Shors et al., 2007).

Much less is known about the effects of repeated stress during gestation on neural plasticity in the pregnant and postpartum female (Table 3). Recent work has shown that repeated restraint stress, 3 times a day for 45 minutes, during late pregnancy (day 11-17), increases the number of proliferating cells in the hippocampus of pregnant females, thus reversing the decrease in cell proliferation seen during late pregnancy (Pawluski et al., 2015; Pawluski et al., 2011). This same stress protocol also increased hippocampal cell proliferation in age-matched virgin females (Pawluski et al., 2011). There was no effect of stress on new cell survival in the hippocampus during late pregnancy, and at matched time points in virgin females, as measured by bromodeoxyuridine (BrdU) techniques (Pawluski et al., 2011). Interestingly, when the same stressor was given earlier during pregnancy, between days 5-11, these early stressed pregnant females had significantly more proliferating cells than nonstressed pregnant females, and significantly more immature neurons in the hippocampus compared to stressed virgin females (Pawluski et al., 2015). Again, no changes in new cell survival were evident during pregnancy or in response to stress (Pawluski et al., 2015). Three hours per day of repeated restraint stress for the last week of pregnancy has also been shown to decrease brain-derived neurotrophic factor (BDNF) and its receptor, TrkB, in the hippocampus of the pregnant female (Maghsoudi et al., 2014), demonstrating again the effects of stress during pregnancy on plasticity in the maternal brain. 
When looking at the effects of stress during pregnancy on dendritic remodeling, restraint stress, for one hour per day, during the last two weeks of pregnancy resulted in significantly shorter apical dendrites and fewer apical branch points in CA3 pyramidal cells in late pregnant females compared to age-matched virgin females, with no effects on dendritic remodeling of CA1 pyramidal cells (Pawluski et al., 2012b).

Stress can also affect plasticity in the maternal brain during lactation and after weaning. Recent work has shown that repeated restraint during lactation reverses the reduction in hippocampal neurogenesis in the maternal brain at this time (Hillerer et al., 2014b) however there appear to be little effects of gestational stress on hippocampal neurogenesis at the time of weaning (Pawluski et al., 2012a). Interestingly exogenous treatment of high levels of corticosterone during lactation further decrease hippocampal cell proliferation and decrease dendritic complexity on CA3 pyramidal cells, while increasing CA3 mushroom spines, in the mother at the time of weaning (Brummelte and Galea, 2010; Workman et al., 2013). (For a summary of effects see Table 3.). Gestational stress can also have a long term impact on plasticity in the maternal brain and can completely abolish the enduring increase in hippocampal LTP in the mother (Lemaire et al., 2006). Recent work is also showing enduring effects of gestational stress on dendritic and spine complexity in other areas of the maternal circuit (Haim et al., 2014; Leuner et al., 2014).

In humans, a growing body of research is showing wide spread changes in many brain areas in women with affective symptoms, postpartum depression and impaired interaction with young [For review see (Moses-Kolko et al., 2014)]. Thus, prolonged and repeated stress, maternal mood, and mental illness are associated with remodeling of the maternal brain. Although the evolutionary significance of the effects of prolonged stress and maternal mood disorders have yet to be determined, it is possible that prolonged and repeated stress may act to alter neuroplasticity and behavior in the mother in such a way that facilitates reproductive success, offspring survival and offspring resilience to the environment they have been born into. Unfortunately, in the case of maternal mood disorders, a child may be able to adapt to the home environment - by being an 'easy' child who can take care of her/him self - but may not function well in other environments such as with peers. For further discussion of the effects of stress on maternal care of offspring see Brummelte and Galea this edition.

\section{General Conclusion}

In closing, it should be apparent that the maternal brain is the very definition of a plastic organ. Beginning early in the female's life, there are significant alterations of neuronal 
structure and activity as the hormones associated with the reproductive cycle begin their lifelong fluctuations, bringing with them the substrate-altering modifications that produce the estrus cycle and sexual behavior. Next, pregnancy, a developmental epoch as significant as sexual differentiation and puberty, sets into motion a series of events ranging from longlasting neuronal structural change, to neurogenesis, to wholesale remodeling of synapses and neural activity, all of which are vulnerable to the effects of stress. Under healthy conditions, the female brain transforms into a motivated, maternal mechanism. And this change, which marks the female now as a mother, appears to remain a part of the female well out to the latter stages of her life, well into senescence. Perhaps this change ensures that grandmothers recognize and will care for young, and aunts for nieces and nephews, but it is a question complicated by the relative sophistication of rodent social structures compared to others (including humans), and highlights necessary precautions when interpreting such complex data. Notwithstanding, it is clear that reproduction equals significant and long-lasting change that is both telling and which has deep roots that extend into the mammal's evolutionary history. 


\section{Figure Legends}

Figure 1. Contraspecific maternal motivation. Semi-free ranging capuchin female carrying a raccoon kit after abducting it from its natural mother. Photo by Alex Huhman. Figure 2. Key brain areas important for maternal behaviors in the rat. AMYG, amygdala; BNST, bed nucleus of the stria terminalis; MPOA, medial preoptic area of the hypothalamus; NAc, nucleus accumbens; OB, olfactory bulb; PAG, periaqueductal grey; mPFC, medial prefrontal cortex; PVN, paraventricular nucleus of hypothalamus; VTA, ventral tegmental area. Brain schematic adapted from Paxinos and Watson ( $5^{\text {th }}$ Edition).

Figure 3. Conserved maternal neural areas. In addition to the areas listed in the figure that have been conserved in both animal and human models, human fMRI studies have identified a functional role for the medial prefrontal cortex, insula, ventral striatum and thalamus in the production and maintenance of maternal behavior. Photo by Lara Lambert. 


\section{References}

Aimone, J.B., Deng, W., Gage, F.H., 2010. Adult neurogenesis: integrating theories and separating functions. Trends Cogn Sci 14, 325-337.

Amaral, D., Witter, M., 1995. Hippocampal Formation, in: Paxinos, G. (Ed.), The rat nervous system, 2nd ed. Academic Press, San Diego.

Baker, S., Chebli, M., Rees, S., Lemarec, N., Godbout, R., Bielajew, C., 2008. Effects of gestational stress: 1. Evaluation of maternal and juvenile offspring behavior. Brain Res. 1213, 98-110.

Banasr, M., Hery, M., Brezun, J.M., Daszuta, A., 2001. Serotonin mediates oestrogen stimulation of cell proliferation in the adult dentate gyrus. Eur.J Neurosci. 14, 1417-1424.

Bardi, M., Eckles, M., Kirk, E., Landis, T., Evans, S., Lambert, K.G., 2014. Parity modifies endocrine hormones in urine and problem-solving strategies of captive owl monkeys (Aotus spp.). Comparative medicine 64, 486-495.

Barha, C.K., Galea, L.A., 2011. Motherhood alters the cellular response to estrogens in the hippocampus later in life. Neurobiol Aging 32, 2091-2095.

Bartels, A., Zeki, S., 2004. The neural correlates of maternal and romantic love. Neuroimage 21, 1155-1166.

Bennett, D.A., Wilson, R.S., Schneider, J.A., Evans, D.A., Mendes de Leon, C.F., Arnold, S.E., Barnes, L.L., Bienias, J.L., 2003. Education modifies the relation of AD pathology to level of cognitive function in older persons. Neurology 60, 1909-1915.

Bennett, H.A., Einarson, A., Taddio, A., Koren, G., Einarson, T.R., 2004. Prevalence of depression during pregnancy: systematic review. Obstet Gynecol 103, 698-709.

Beversdorf, D.Q., Manning, S.E., Hillier, A., Anderson, S.L., Nordgren, R.E., Walters, S.E., Nagaraja, H.N., Cooley, W.C., Gaelic, S.E., Bauman, M.L., 2005. Timing of prenatal stressors and autism. J Autism Dev Disord 35, 471-478.

Bridges, R.S., 2014. Neuroendocrine regulation of maternal behavior. Front Neuroendocrinol.

Brummelte, S., Galea, L.A., 2010. Chronic corticosterone during pregnancy and postpartum affects maternal care, cell proliferation and depressive-like behavior in the dam. Horm Behav. 58, 769-779. 
Brus, M., Meurisse, M., Franceschini, I., Keller, M., Levy, F., 2010. Evidence for cell proliferation in the sheep brain and its down-regulation by parturition and interactions with the young. . Hormones and behavior 58, 737-746.

Buckwalter, J.G., Buckwalter, D.K., Bluestein, B.W., Stanczyk, F.Z., 2001. Pregnancy and post partum: changes in cognition and mood. Prog.Brain Res. 133, 303-319.

Buss, D.M., 2003. The Evolution of Desire. Basic Books.

Byrnes, E.M., Bridges, R.S., 2006. Reproductive experience alters anxiety-like behavior in the female rat. Horm Behav. 50, 70-76.

Christensen, H., Leach, L.S., Mackinnon, A., 2010. Cognition in pregnancy and moterhood:prospective cohort study. Britsh Journal of Psychiatry 196, 126-132.

Cohen, J., Bridges, R., 1981. Retention of maternal behavior in nulliparous and primiparous rats: Effects of duration of previous maternal experience. Journal of Comparative and Physiological Psychology 95, 450-459.

Colucci, M., Cammarata, S., Assini, A., Croce, R., Clerici, F., Novello, C., Mazzella, L., Dagnino, N., Mariani, C., Tanganelli, P., 2006. The number of pregnancies is a risk factor for Alzheimer's disease. Eur J Neurol 13, 1374-1377.

Crawley, R.A., Dennison, K., Carter, C., 2003. Cognition in pregnancy and the first year post-partum. Psychol Psychother 76, 69-84.

Cui, J., Jothishankar, B., He, P., Staufenbiel, M., Shen, Y., Li, R., 2014. Amyloid precursor protein mutation disrupts reproductive experience-enhanced normal cognitive development in a mouse model of Alzheimer's disease. Mol Neurobiol 49, 103-122.

Cuttler, C., Graf, P., Pawluski, J.L., Galea, L.A., 2011. Everyday life memory deficits in pregnant women. Can J Exp Psychol 65, 27-37.

Darnaudery, M., Dutriez, I., Viltart, O., Morley-Fletcher, S., Maccari, S., 2004. Stress during gestation induces lasting effects on emotional reactivity of the dam rat. Behav Brain Res 153, 211-216.

Darnaudery, M., Perez-Martin, M., Del Favero, F., Gomez-Roldan, C., Garcia-Segura, L.M., Maccari, S., 2007. Early motherhood in rats is associated with a modification of hippocampal function. Psychoneuroendocrinology 32, 803-812. 
de Groot, R.H., Vuurman, E.F., Hornstra, G., Jolles, J., 2006. Differences in cognitive performance during pregnancy and early motherhood. Psychological medicine 36, 10231032.

Douglas, A.J., Brunton, P.J., Bosch, O.J., Russell, J.A., Neumann, I.D., 2003. Neuroendocrine responses to stress in mice: hyporesponsiveness in pregnancy and parturition. Endocrinology 144, 5268-5276.

Eisch, A.J., Cameron, H.A., Encinas, J.M., Meltzer, L.A., Ming, G.L., Overstreet-Wadiche, L.S., 2008. Adult neurogenesis, mental health, and mental illness: hope or hype? J Neurosci. $28,11785-11791$.

Engert, F., Bonhoeffer, T., 1999. Dendritic spine changes associated with hippocampal longterm synaptic plasticity. Nature 399, 66-70.

Falconer, E.M., Galea, L.A., 2003. Sex differences in cell proliferation, cell death and defensive behavior following acute predator odor stress in adult rats. Brain Res. 975, 22-36.

Feldman, R., Weller, A., Zagoory-Sharon, O., Levine, A., 2007. Evidence for a neuroendocrinological foundation of human affiliation: plasma oxytocin levels across pregnancy and the postpartum period predict mother-infant bonding. Psychol Sci 18, 965970.

Fleming, A.S., 2007. The three faces of Jay S. Rosenblatt. Dev Psychobiol 49, 2-11.

Fleming, A.S., Kraemer, G.W., Gonzalez, A., Lovic, V., Rees, S., Melo, A., 2002. Mothering begets mothering: the transmission of behavior and its neurobiology across generations. Pharmacol.Biochem.Behav. 73, 61-75.

Fleming, A.S., Luebke, C., 1981. Timidity prevents the virgin female rat from being a good mother: emotionality differences between nulliparous and parturient females. Physiol Behav $27,863-868$.

Fleming, A.S., O'Day, D.H., Kraemer, G.W., 1999. Neurobiology of mother-infant interactions: experience and central nervous system plasticity across development and generations. Neurosci Biobehav Rev 23, 673-685.

Fleming, A.S., Vaccarino, F., Luebke, C., 1980. Amygdaloid inhibition of maternal behavior in the nulliparous female rat. Physiol Behav 25, 731-743.

Frankfurt, M., Salas-Ramirez, K., Friedman, E., Luine, V., 2011. Cocaine alters dendritic spine density in cortical and subcortical brain regions of the postpartum and virgin female rat. Synapse 65, 955-961. 
Franssen, R.A., Rzucidlo, A.M., Franssen, C.L., Hampton, J.E., Benkovic, S.A., Jr., Bardi, M., Kinsley, C.H., Lambert, K.G., 2012. Reproductive experience facilitates recovery from kainic acid-induced neural insult in female Long-Evans rats. Brain Res. 1454, 80-89.

Furuta, M., Bridges, R.S., 2005. Gestation-induced cell proliferation in the rat brain. Brain Res Dev Brain Res 156, 61-66.

Galea, L., Ormerod, B., Sampath, S., Kostaras, X., Wilkie, D., Phelps, M., 2000. Spatial working memory and hippocampal size across pregnancy in rats. Hormones and Behaviour $37,86-95$.

Galea, L.A., Leuner, B., Slattery, D.A., 2014. Hippocampal plasticity during the peripartum period: influence of sex steroids, stress and ageing. J Neuroendocrinol. 26, 641-648.

Galea, L.A., McEwen, B.S., 1999. Sex and seasonal differences in the rate of cell proliferation in the dentate gyrus of adult wild meadow voles. Neuroscience 89, 955-964.

Galea, L.A., Wainwright, S.R., Roes, M.M., Duarte-Guterman, P., Chow, C., Hamson, D.K., 2013. Sex, hormones, and neurogenesis in the hippocampus: Hormonal modulation of neurogenesis and potential functional implications. J Neuroendocrinol.

Gangestad, S.W., Thornhill, R., Yeo, R.A., 1994. Facial attractiveness, developmental stability, and fluctuating asymmetry. Ethology and Sociobiology 15, 73-85.

Garthe, A., Kempermann, G., 2013. An old test for new neurons: refining the Morris water maze to study the functional relevance of adult hippocampal neurogenesis. Frontiers in neuroscience 7, 63 .

Gascon, E., Vutskits, L., Jenny, B., Durbec, P., Kiss, J.Z., 2007. PSA-NCAM in postnatally generated immature neurons of the olfactory bulb: a crucial role in regulating p75 expression and cell survival. Development 134, 1181-1190.

Gatewood, J.D., Morgan, M.D., Eaton, M., McNamara, I.M., Stevens, L.F., Macbeth, A.H., Meyer, E.A., Lomas, L.M., Kozub, F.J., Lambert, K.G., Kinsley, C.H., 2005. Motherhood mitigates aging-related decrements in learning and memory and positively affects brain aging in the rat. Brain Res.Bull. 66, 91-98.

Glasper, E.R., Kozorovitskiy, Y., Pavlic, A., Gould, E., 2011. Paternal experience suppresses adult neurogenesis without altering hippocampal function in Peromyscus californicus. The Journal of comparative neurology 519, 2271-2281.

Glover, V., O'Connor, T.G., O'Donnell, K., 2009. Prenatal stress and the programming of the HPA axis. Neurosci Biobehav Rev. 
Haim, A., Sherer, M., Leuner, B., 2014. Gestational stress induces persistent depressive-like behavior and structural modifications within the postpartum nucleus accumbens. Eur.J Neurosci. 40, 3766-3773.

Henschen, C.W., Palmiter, R.D., Darvas, M., 2013. Restoration of dopamine signaling to the dorsal striatum is sufficient for aspects of active maternal behavior in female mice. Endocrinology 154, 4316-4327.

Hillerer, K.M., Jacobs, V.R., Fischer, T., Aigner, L., 2014a. The maternal brain: an organ with peripartal plasticity. Neural Plast 2014, 574159.

Hillerer, K.M., Neumann, I.D., Couillard-Despres, S., Aigner, L., Slattery, D.A., 2014b. Lactation-induced reduction in hippocampal neurogenesis is reversed by repeated stress exposure. Hippocampus 24, 673-683.

Hillerer, K.M., Reber, S.O., Neumann, I.D., Slattery, D.A., 2011. Exposure to chronic pregnancy stress reverses peripartum-associated adaptations: implications for postpartum anxiety and mood disorders. Endocrinology 152, 3930-3940.

Huang, Y., Shi, X., Xu, H., Yang, H., Chen, T., Chen, S., Chen, X., 2010. Chronic unpredictable stress before pregnancy reduce the expression of brain-derived neurotrophic factor and N-methyl-D-aspartate receptor in hippocampus of offspring rats associated with impairment of memory. Neurochem Res 35, 1038-1049.

Huizink, A.C., Mulder, E.J., Buitelaar, J.K., 2004. Prenatal stress and risk for psychopathology: specific effects or induction of general susceptibility? Psychol.Bull. 130, 115-142.

Huizink, A.C., Robles de Medina, P.G., Mulder, E.J., Visser, G.H., Buitelaar, J.K., 2003. Stress during pregnancy is associated with developmental outcome in infancy. J Child Psychol Psychiatry 44, 810-818.

Humphrey, T., 1967. Evolution of the Forebrain, in: Hasler, R., Stephan, H. (Eds.). Plenum, New York, pp. 104-116.

Kappers, C.U.A., Huber, C.G., Crosby, E.C., , 1936. The comparative anatomy of the nervous system of vertebrates, including Man. Macmillan, New York.

Kempermann, G., 2012. New neurons for 'survival of the fittest'. Nat Rev Neurosci 13, 727736. 
Kesner, R.P., Dakis, M., 1995. Phencyclidine injections into the dorsal hippocampus disrupt long- but not short-term memory within a spatial learning task. Psychopharmacology (Berl) 120, 203-208.

Keyser-Marcus, L., Stafisso-Sandoz, G., Gerecke, K., Jasnow, A., Nightingale, L., Lambert, K.G., Gatewood, J., Kinsley, C.H., 2001. Alterations of medial preoptic area neurons following pregnancy and pregnancy-like steroidal treatment in the rat. Brain Res.Bull. 55, 737-745.

Kinsley, C.H., Blair, J.C., Karp, N.E., Hester, N.W., McNamara, I.M., Orthmeyer, A.L., McSweeney, M.C., Bardi, M.M., Karelina, K., Christon, L.M., Sirkin, M.R., Victoria, L.W., Skurka, D.J., Fyfe, C.R., Hudepohl, M.B., Felicio, L.F., Franssen, R.A., Meyer, E.E., da Silva, I.S., Lambert, K.G., 2014. The mother as hunter: significant reduction in foraging costs through enhancements of predation in maternal rats. Horm Behav. 66, 649-654.

Kinsley, C.H., Franssen, R.A., Meyer, E.A., 2012a. Reproductive experience may positively adjust the trajectory of senescence. Current topics in behavioral neurosciences 10, 317-345.

Kinsley, C.H., Lambert, K.G., 2006. The maternal brain. Sci Am 294, $72-79$.

Kinsley, C.H., Madonia, L., Gifford, G.W., Tureski, K., Griffin, G.R., Lowry, C., Williams, J., Collins, J., McLearie, H., Lambert, K.G., 1999. Motherhood improves learning and memory. Nature 402, 137-138.

Kinsley, C.H., Meyer, E., Rafferty, K.A., 2012b. Sex steroid hormone determination of the maternal brain: effects beyond reproduction. Mini reviews in medicinal chemistry 12, 1063 1070 .

Kinsley, C.H., Trainer, R., Stafisso-Sandoz, G., Quadros, P., Marcus, L.K., Hearon, C., Meyer, E.A., Hester, N., Morgan, M., Kozub, F.J., Lambert, K.G., 2006. Motherhood and the hormones of pregnancy modify concentrations of hippocampal neuronal dendritic spines. Horm Behav. 49, 131-142.

Lambert, K.G., 2012. The parental brain: transformations and adaptations. Physiol Behav 107, 792-800.

Lambert, K.G., Berry, A.E., Griffins, G., Amory-Meyers, E., Madonia-Lomas, L., Love, G., Kinsley, C.H., 2005. Pup exposure differentially enhances foraging ability in primiparous and nulliparous rats. Physiol Behav 84, 799-806.

Lambert, K.G., Franssen, C.L., Bardi, M., Hampton, J.E., Hainley, L., Karsner, S., Tu, E.B., Hyer, M.M., Crockett, A., Baranova, A., Ferguson, T., Ferguson, T., Kinsley, C.H., 2011. Characteristic neurobiological patterns differentiate paternal responsiveness in two Peromyscus species. Brain Behav Evol 77, 159-175. 
Lambert, K.G., Franssen, C.L., Hampton, J.E., Rzucidlo, A.M., Hyer, M.M., True, M., Kaufman, C., Bardi, M., 2013. Modeling paternal attentiveness: distressed pups evoke differential neurobiological and behavioral responses in paternal and nonpaternal mice. Neuroscience 234, 1-12.

Lancaster, C.A., Gold, K.J., Flynn, H.A., Yoo, H., Marcus, S.M., Davis, M.M., 2010. Risk factors for depressive symptoms during pregnancy: a systematic review. Am.J Obstet.Gynecol. 202, 5-14.

Laplante, D.P., Barr, R.G., Brunet, A., Galbaud du Fort, G., Meaney, M.L., Saucier, J.F., Zelazo, P.R., King, S., 2004. Stress during pregnancy affects general intellectual and language functioning in human toddlers. Pediatr Res 56, 400-410.

Larsen, C.M., Grattan, D.R., 2012. Prolactin, neurogenesis, and maternal behaviors. Brain Behav Immun 26, 201-209.

Larsen, C.M., Kokay, I.C., Grattan, D.R., 2008. Male pheromones initiate prolactin-induced neurogenesis and advance maternal behavior in female mice. Horm Behav. 53, 509-517.

LeDoux, J., 1996. The emotional brain. Simon and Schuster, New York.

Lee, A., Clancy, S., Fleming, A.S., 1999a. Mother rats bar-press for pups: effects of lesions of the mpoa and limbic sites on maternal behavior and operant responding for pupreinforcement. Behav Brain Res 100, 15-31.

Lee, A., Li, M., Watchus, J., Fleming, A.S., 1999b. Neuroanatomical basis of maternal memory in postpartum rats: Selective role for the nucleus accumbens. Behavioural Neuroscience 113, 523-538.

Lemaire, V., Billard, J.M., Dutar, P., George, O., Piazza, P.V., Epelbaum, J., Le Moal, M., Mayo, W., 2006. Motherhood-induced memory improvement persists across lifespan in rats but is abolished by a gestational stress. Eur.J Neurosci. 23, 3368-3374.

Leuner, B., Fredericks, P.J., Nealer, C., Albin-Brooks, C., 2014. Chronic gestational stress leads to depressive-like behavior and compromises medial prefrontal cortex structure and function during the postpartum period. PLoS One 9, e89912.

Leuner, B., Glasper, E.R., Gould, E., 2010. Parenting and plasticity. Trends Neurosci 33, 465-473.

Leuner, B., Gould, E., 2010. Dendritic growth in medial prefrontal cortex and cognitive flexibility are enhanced during the postpartum period. J Neurosci. 30, 13499-13503. 
Leuner, B., Mirescu, C., Noiman, L., Gould, E., 2007. Maternal experience inhibits the production of immature neurons in the hippocampus during the postpartum period through elevations in adrenal steroids. Hippocampus 17, 434-442.

Levy, F., 2008. Neural substrates involved in the onset of maternal responsiveness and selectivity in sheep, in: Bridges, R.S. (Ed.), Neurobiology of the parental brain. Elsevier, New York.

Levy, F., Gheusi, G., Keller, M., 2011. Plasticity of the parental brain: a case for neurogenesis. J Neuroendocrinol. 23, 984-993.

Lonstein, J.S., 2005. Reduced anxiety in postpartum rats requires recent physical interactions with pups, but is independent of suckling and peripheral sources of hormones. Horm Behav. 47, 241-255.

Lorberbaum, J.P., Newman, J.D., Dubno, J.R., Horwitz, A.R., Nahas, Z., Teneback, C.C., Bloomer, C.W., Bohning, D.E., Vincent, D., Johnson, M.R., Emmanuel, N., BrawmanMintzer, O., Book, S.W., Lydiard, R.B., Ballenger, J.C., George, M.S., 1999. Feasibility of using fMRI to study mothers responding to infant cries. Depress Anxiety 10, 99-104.

Lorberbaum, J.P., Newman, J.D., Horwitz, A.R., Dubno, J.R., Lydiard, R.B., Hamner, M.B., Bohning, D.E., George, M.S., 2002. A potential role for thalamocingulate circuitry in human maternal behavior. Biol.Psychiatry 51, 431-445.

Lott, D.F., Rosenblatt, J.S., 1969. Development of maternal responsiveness during pregnancy in the rat, in: Foss, B.F. (Ed.), Determinants of infant behavior IV. Methuen, London, pp. 6167.

Love, G., Torrey, N., McNamara, I., Morgan, M., Banks, M., Hester, N.W., Glasper, E.R., Devries, A.C., Kinsley, C.H., Lambert, K.G., 2005. Maternal experience produces longlasting behavioral modifications in the rat. Behav.Neurosci. 119, 1084-1096.

Macbeth, A.H., Scharfman, H.E., Maclusky, N.J., Gautreaux, C., Luine, V.N., 2008. Effects of multiparity on recognition memory, monoaminergic neurotransmitters, and brain-derived neurotrophic factor (BDNF). Horm Behav. 54, 7-17.

Maccari, S., Morley-Fletcher, S., 2007. Effects of prenatal restraint stress on the hypothalamus-pituitary-adrenal axis and related behavioural and neurobiological alterations. Psychoneuroendocrinology 32 Suppl 1, S10-15.

MacLean, P., 1990. The triune brain. Plenum Press, New York. 
Maghsoudi, N., Ghasemi, R., Ghaempanah, Z., Ardekani, A.M., Nooshinfar, E., Tahzibi, A., 2014. Effect of Chronic Restraint Stress on HPA Axis Activity and Expression of BDNF and Trkb in the Hippocampus of Pregnant Rats: Possible Contribution in Depression during Pregnancy and Postpartum Period. Basic and clinical neuroscience 5, 131-137.

Mattson, B.J., Williams, S.E., Rosenblatt, J.S., Morrell, J.I., 2003. Preferences for cocaine- or pup-associated chambers differentiates otherwise behaviorally identical postpartum maternal rats. Psychopharmacology (Berl) 167, 1-8.

McEwen, B., 2002. Estrogen actions throughout the brain. Recent Prog Horm Res 57, 357384.

Morgan, C.A., 3rd, Rasmusson, A., Pietrzak, R.H., Coric, V., Southwick, S.M., 2009. Relationships among plasma dehydroepiandrosterone and dehydroepiandrosterone sulfate, cortisol, symptoms of dissociation, and objective performance in humans exposed to underwater navigation stress. Biol.Psychiatry 66, 334-340.

Morgan, H.D., Watchus, J.A., Milgram, N.W., Fleming, A.S., 1999. The long lasting effects of electrical simulation of the medial preoptic area and medial amygdala on maternal behavior in female rats. Behav Brain Res 99, 61-73.

Moses-Kolko, E.L., Horner, M.S., Phillips, M.L., Hipwell, A.E., Swain, J.E., 2014. In search of neural endophenotypes of postpartum psychopathology and disrupted maternal caregiving. J Neuroendocrinol. 26, 665-684.

Neumann, I.D., Johnstone, H.A., Hatzinger, M., Liebsch, G., Shipston, M., Russell, J.A., Landgraf, R., Douglas, A.J., 1998. Attenuated neuroendocrine responses to emotional and physical stressors in pregnant rats involve adenohypophysial changes. J Physiol 508 ( Pt 1), 289-300.

Niederhofer, H., Reiter, A., 2004. Prenatal maternal stress, prenatal fetal movements and perinatal temperament factors influence behavior and school marks at the age of 6 years. Fetal Diagn Ther 19, 160-162.

Numan, M., 1988. Neural basis of maternal behavior in the rat. Psychoneuroendocrinology $13,47-62$.

Numan, M., 2007. Motivational systems and the neural circuitry of maternal behavior in the rat. Dev Psychobiol 49, 12-21.

Numan, M., Fleming, A.S., Levy, F., 2006. Maternal behavior, in: D., N.J. (Ed.), Knobil and Neill's Physiology of Reproduction, 3rd Edition. Elsevier, pp. 1921-1993.

Numan, M., Insel, T.R., 2003. The neurobiology of parental behavior. Springer, New York. 
Numan, M., Numan, M.J., 1997. Projection sites of medial preoptic area and ventral bed nucleus of the stria terminalis neurons that express Fos during maternal behavior in female rats. J Neuroendocrinol. 9, 369-384.

Numan, M., Stolzenberg, D.S., 2008. Hypothalamic interaction with the mesolimbic dopamine system and the regulation of maternal responsiveness, in: Bridges, R.S. (Ed.), Neurobiology of the parental brain. Elsevier, New York.

O'Mahony, S.M., Myint, A.M., van den Hove, D., Desbonnet, L., Steinbusch, H., Leonard, B.E., 2006. Gestational stress leads to depressive-like behavioural and immunological changes in the rat. Neuroimmunomodulation 13, 82-88.

Oatridge, A., Holdcroft, A., Saeed, N., Hajnal, J.V., Puri, B.K., Fusi, L., Bydder, G.M., 2002. Change in brain size during and after pregnancy: study in healthy women and women with preeclampsia. AJNR Am J Neuroradiol 23, 19-26.

Oberlander, T.F., Gingrich, J.A., Ansorge, M.S., 2009. Sustained neurobehavioral effects of exposure to SSRI antidepressants during development: molecular to clinical evidence. Clin Pharmacol Ther 86, 672-677.

Parsons, T.D., Thompson, E., Buckwalter, D.K., Bluestein, B.W., Stanczyk, F.Z., Buckwalter, J.G., 2004. Pregnancy history and cognition during and after pregnancy. Int J Neurosci 114, 1099-1110.

Pawluski, J.L., Barakauskas, V.E., Galea, L.A., 2010. Pregnancy decreases oestrogen receptor alpha expression and pyknosis, but not cell proliferation or survival, in the hippocampus. J Neuroendocrinol. 22, 248-257.

Pawluski, J.L., Brummelte, S., Barha, C.K., Crozier, T.M., Galea, L.A., 2009. Effects of steroid hormones on neurogenesis in the hippocampus of the adult female rodent during the estrous cycle, pregnancy, lactation and aging. Front Neuroendocrinol 30, 343-357.

Pawluski, J.L., Charlier, T.D., Fillet, M., Houbart, V., Crispin, H.T., Steinbusch, H.W., van den Hove, D.L., 2012a. Chronic fluoxetine treatment and maternal adversity differentially alter neurobehavioral outcomes in the rat dam. Behav Brain Res 228, 159-168.

Pawluski, J.L., Csaszar, E., Savage, E., Martinez-Claros, M., Steinbusch, H.W., van den Hove, D., 2015. Effects of stress early in gestation on hippocampal neurogenesis and glucocorticoid receptor density in pregnant rats. Neuroscience 290C, 379-388.

Pawluski, J.L., Galea, L.A., 2006. Hippocampal morphology is differentially affected by reproductive experience in the mother. J Neurobiol. 66, 71-81. 
Pawluski, J.L., Galea, L.A., 2007. Reproductive experience alters hippocampal neurogenesis during the postpartum period in the dam. Neuroscience 149, 53-67.

Pawluski, J.L., Galea, L.A., 2008. The role of reproductive experience on hippocampal function and plasticity, in: Bridges, R. (Ed.), Neurobiology of the Parental Brain. Academic Press, Boston, pp. 493-508.

Pawluski, J.L., Valenca, A., Santos, A.I., Costa-Nunes, J.P., Steinbusch, H.W., Strekalova, T., 2012b. Pregnancy or stress decrease complexity of CA3 pyramidal neurons in the hippocampus of adult female rats. Neuroscience 227, 201-210.

Pawluski, J.L., van den Hove, D.L., Rayen, I., Prickaerts, J., Steinbusch, H.W., 2011. Stress and the pregnant female: Impact on hippocampal cell proliferation, but not affective-like behaviors. Horm Behav. 59, 572-580.

Pawluski, J.L., Vanderbyl, B.L., Ragan, K., Galea, L.A., 2006. First reproductive experience persistently affects spatial reference and working memory in the mother and these effects are not due to pregnancy or 'mothering' alone. Behav Brain Res 175, 157-165.

Pereira, M., Seip, K., Morrell, J.I., 2008. Maternal motivation and its neural substrate across the postpartum period, in: Bridges, R.S. (Ed.), Neurobiology of the parental brain. Elsevier, New York.

Perls, T.T., Alpert, L., Fretts, R.C., 1997. Middle-aged mothers live longer. Nature 389, 133.

Perrin, G., Meurisse, M., Levy, F., 2007. Inactivation of the medial preoptic area or the bed nucleus of the stria terminalis differentially disrupts maternal behavior in sheep. Hormones and behavior 52, 461-473.

Poser, C.M., Kassirer, M.R., Peyser, J.M., 1986. Benign encephalopathy of pregnancy. Acta Neurologica Scandinavia 73, 39-43.

Ptok, U., Barkow, K., Heun, R., 2002. Fertility and number of children in patients with Alzheimer's disease. Arch Womens Ment Health 5, 83-86.

Rhodes, G., 2006. The evolutionary psychology of facial beauty. Annual review of psychology 57, 199-226.

Rolls, A., Schori, H., London, A., Schwartz, M., 2008. Decrease in hippocampal neurogenesis during pregnancy: a link to immunity. Mol.Psychiatry 13, 468-469.

Rosenblatt, J.S., 1967. Nonhormonal basis of maternal behavior in the rat. Science 156, 15121514. 
Rosenblatt, J.S., 1969. The development of maternal responsiveness in the rat. The American journal of orthopsychiatry $39,36-56$.

Rosenblatt, J.S., 1980. Hormonal and nonhormonal regulation of maternal behavior: a theoretical survey. Reproduction, nutrition, development 20, 791-800.

Rosenblatt, J.S., Hazelwood, S., Poole, J., 1996. Maternal behavior in male rats: effects of medial preoptic area lesions and presence of maternal aggression. Horm Behav. 30, 201-215.

Rosenblatt, J.S., Mayer, A.D., 1995. An analysis of approach/withdrawal processes in the initiation of maternal behavior in the laboratory rat, in: Hood, K.E., Greenberg, G., Toback, E. (Eds.), Behavioral Development. Garland Press, New York, pp. 177-230.

Ruscio, M.G., Sweeny, T.D., Hazelton, J.L., Suppatkul, P., Boothe, E., Carter, C.S., 2008. Pup exposure elicits hippocampal cell proliferation in the prairie vole. Behav Brain Res 187, 9-16.

Seki, T., Arai, Y., 1993. Highly polysialylated neural cell adhesion molecule (NCAM-H) is expressed by newly generated granule cells in the dentate gyrus of the adult rat. J Neurosci. $13,2351-2358$.

Sheeman, T., Numan, M., 2002. Estrogen, progesterone, and pregnancy termination alter neural activity in brain regions that control maternal behavior in rats. Neuroendocrinology 75 , 12-23.

Shingo, T., Gregg, C., Enwere, E., Fujikawa, H., Hassam, R., Geary, C., Cross, J.C., Weiss, S., 2003. Pregnancy-stimulated neurogenesis in the adult female forebrain mediated by prolactin. Science 299, 117-120.

Shors, T.J., Mathew, J., Sisti, H.M., Edgecomb, C., Beckoff, S., Dalla, C., 2007. Neurogenesis and helplessness are mediated by controllability in males but not in females. Biol.Psychiatry 62, 487-495.

Slattery, D.A., Neumann, I.D., 2008. No stress please! Mechanisms of stress hyporesponsiveness of the maternal brain. J Physiol 586, 377-385.

Slotnick, B.M., 1967. Distrubances of maternal behavior in the rat following lesions of the cingulate cortex. Behaviour 29, 204-236.

Smith, J.W., Seckl, J.R., Evans, A.T., Costall, B., Smythe, J.W., 2004. Gestational stress induces post-partum depression-like behaviour and alters maternal care in rats. Psychoneuroendocrinology 29, 227-244. 
Sobow, T., Kloszewska, I., 2004. Parity, number of pregnancies, and the age of onset of Alzheimer's disease. J Neuropsychiatry Clin Neurosci 16, 120-121.

Stack, E.C., Balakrishnan, R., Numan, M.J., Numan, M., 2002. A functional neuroanatomical investigation of the role of the medial preoptic area in neural circuits regulating maternal behavior. Behav Brain Res 131, 17-36.

Stewart, D.E., 2011. Clinical practice. Depression during pregnancy. N Engl J Med 365, $1605-1611$.

Strathearn, L., 2002. A 14-year longitudinal study of child neglect: cognitive development and head growth, 14th International Congress on Child Abuse and Neglect, Denver, CO.

Swain, J.E., 2008. Baby stimuli and the parent brain: functional neuroimaging of the neural substrates of parent-infant attachment. Psychiatry (Edgmont) 5, 28-36.

Swain, J.E., 2011. The human parental brain: in vivo neuroimaging. Prog Neuropsychopharmacol Biol Psychiatry 35, 1242-1254.

Swain, J.E., Leckman, J.F., Mayes, L., Feldman, R., 2003. The neural circuitry of parentinfant attachment in the early postpartum attachment in the early postpartum, American College of Neuropsychopharmacology, Peurto Rico.

Talge, N.M., Neal, C., Glover, V., 2007. Antenatal maternal stress and long-term effects on child neurodevelopment: how and why? J Child Psychol Psychiatry 48, 245-261.

Tomizawa, K., Iga, N., Lu, Y.F., Moriwaki, A., Matsushita, M., Li, S.T., Miyamoto, O., Itano, T., Matsui, H., 2003. Oxytocin improves long-lasting spatial memory during motherhood through MAP kinase cascade. Nat.Neurosci. 6, 384-390.

Vallee, M., Mayo, W., Le Moal, M., 2001. Role of pregnenolone, dehydroepiandrosterone and their sulfate esters on learning and memory in cognitive aging. Brain Res Brain Res Rev $37,301-312$.

Van den Bergh, B.R., Mennes, M., Oosterlaan, J., Stevens, V., Stiers, P., Marcoen, A., Lagae, L., 2005. High antenatal maternal anxiety is related to impulsivity during performance on cognitive tasks in 14- and 15-year-olds. Neurosci Biobehav Rev 29, 259-269.

Van den Bergh, B.R., Van Calster, B., Smits, T., Van Huffel, S., Lagae, L., 2008. Antenatal maternal anxiety is related to HPA-axis dysregulation and self-reported depressive symptoms in adolescence: a prospective study on the fetal origins of depressed mood. Neuropsychopharmacology 33, 536-545. 
Van den Hove, D.L., Blanco, C.E., Aendekerk, B., Desbonnet, L., Bruschettini, M., Steinbusch, H.P., Prickaerts, J., Steinbusch, H.W., 2005. Prenatal restraint stress and longterm affective consequences. Dev Neurosci 27, 313-320.

Vivar, C., van Praag, H., 2013. Functional circuits of new neurons in the dentate gyrus. Frontiers in neural circuits $7,15$.

Wainwright, S.R., Galea, L.A., 2013. The Neural Plasticity Theory of Depression: Assessing the Roles of Adult Neurogenesis and PSA-NCAM within the Hippocampus. Neural Plast $2013,805497$.

Wartella, J., Amory, E., Lomas, L.M., Macbeth, A., McNamara, I., Stevens, L., Lambert, K.G., Kinsley, C.H., 2003. Single or multiple reproductive experiences attenuate neurobehavioral stress and fear responses in the female rat. Physiol Behav 79, 373-381.

Weinstock, M., 2007. Gender differences in the effects of prenatal stress on brain development and behaviour. Neurochem Res 32, 1730-1740.

Wemm, S., Koone, T., Blough, E.R., Mewaldt, S., Bardi, M., 2010. The role of DHEA in relation to problem solving and academic performance. Biol.Psychol. 85, 53-61.

Westenbroek, C., Den Boer, J.A., Veenhuis, M., Ter Horst, G.J., 2004. Chronic stress and social housing differentially affect neurogenesis in male and female rats. Brain Res.Bull. 64, 303-308.

Workman, J.L., Brummelte, S., Galea, L.A., 2013. Postpartum corticosterone administration reduces dendritic complexity and increases the density of mushroom spines of hippocampal CA3 arbours in dams. J Neuroendocrinol. 25, 119-130.

Workman, J.L., Raineki, C., Weinberg, J., Galea, L.A., in press. Alcohol and pregnancy: Effects on maternal care, HPA axis function, and hippocampal neurogenesis in adult females. Psychoneuroendocrinology. 


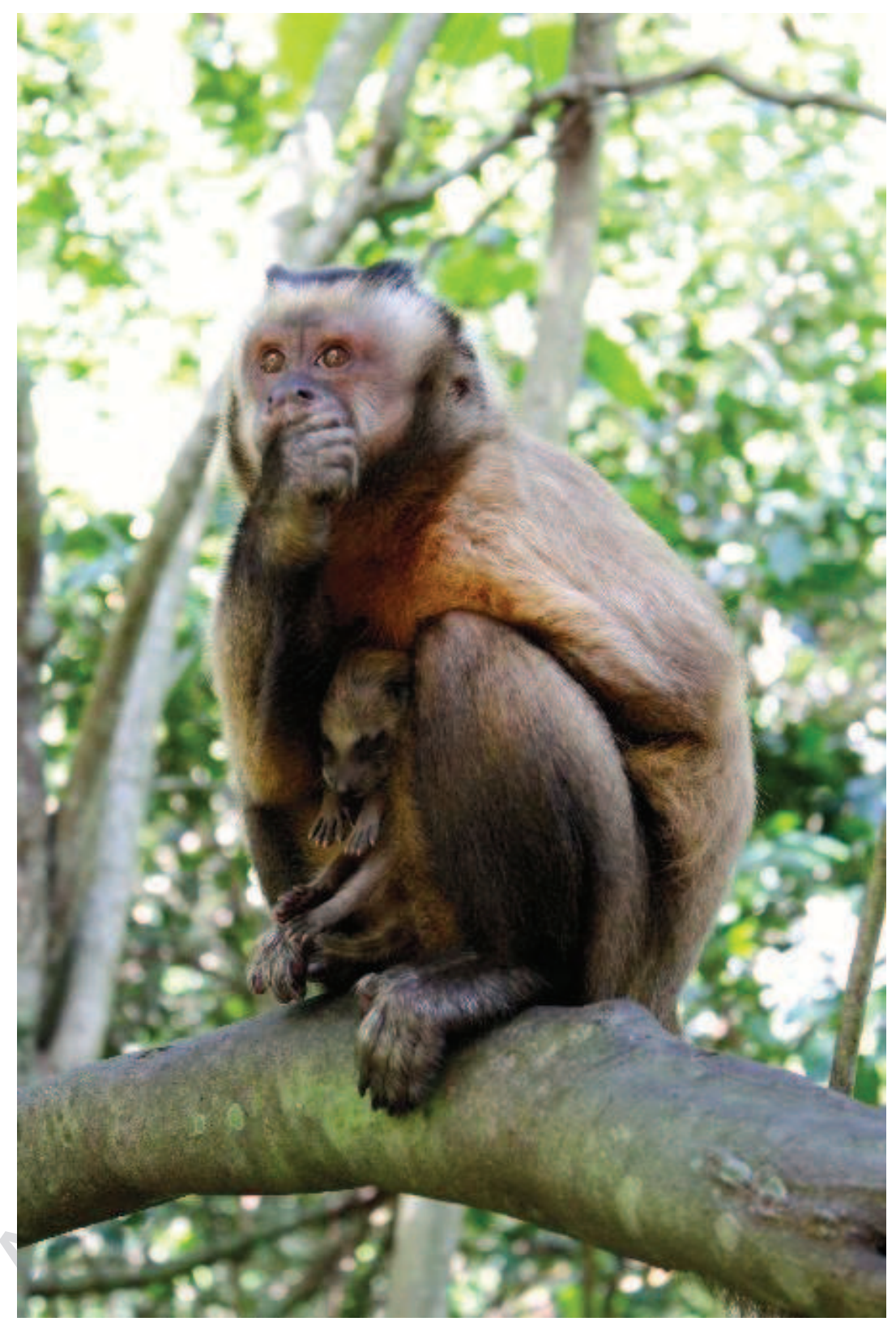

Figure 1. Contraspecific maternal motivation. Semi-free ranging capuchin female carrying a raccoon kit after abducting it from its natural mother. Photo by Alex Huhman. 


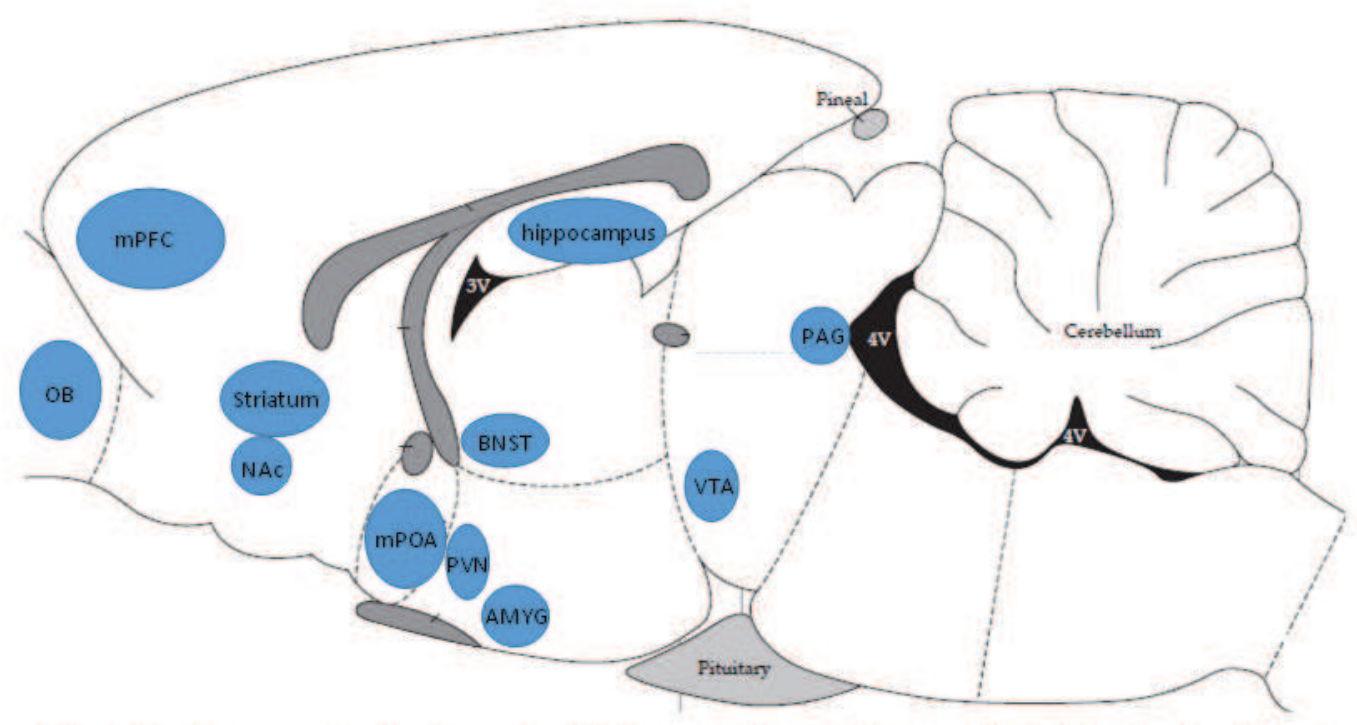

Figure 2. Key brain areas important for maternal behaviors in the rat. AMYG, amygdala; BNST, bed nucleus of the stria terminalis; MPOA, medial preoptic area of the hypothalamus; NAc, nucleus accumbens; $O B$, olfactory bulb; $P A G$, periaqueductal grey; $\mathrm{PPFC}$, medial prefrontal cortex: PVN, paraventricular nucleus of hypothalamus; VTA, ven tral tegmental area. Brain schematic adapted from Paxinos and Watson ( $5^{\text {th }}$ Edition). 


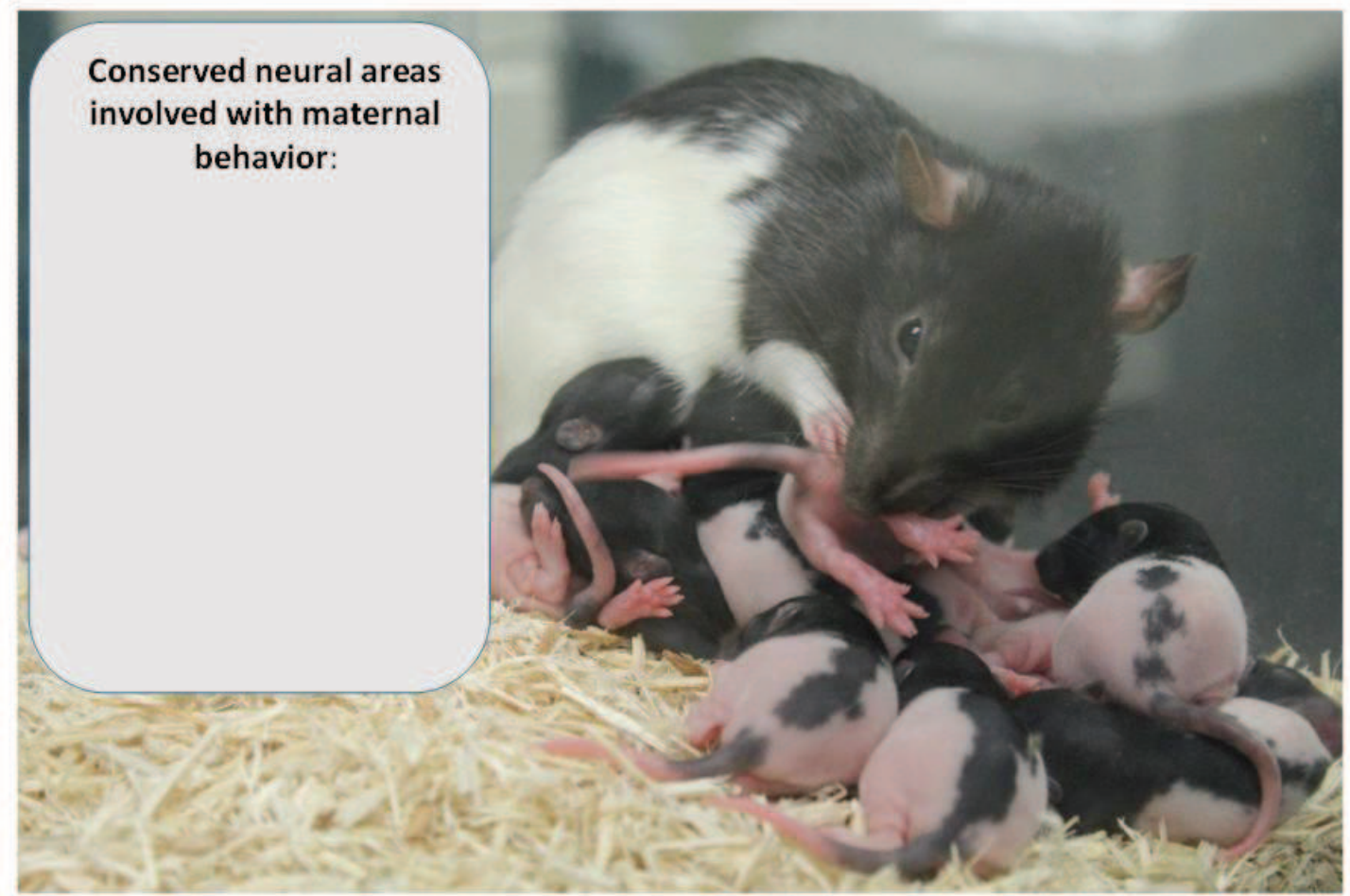

Figure 3. Conserved maternal neural areas. In addition to the areas listed in the figure that have been conserved in both animal and human models, human fMRI studies have identified a functional role for the medial prefrontal cortex, insula, ventral striatum and thalamus in the production and maintenance of maternal behavior. Photo by Lara Lambert. 


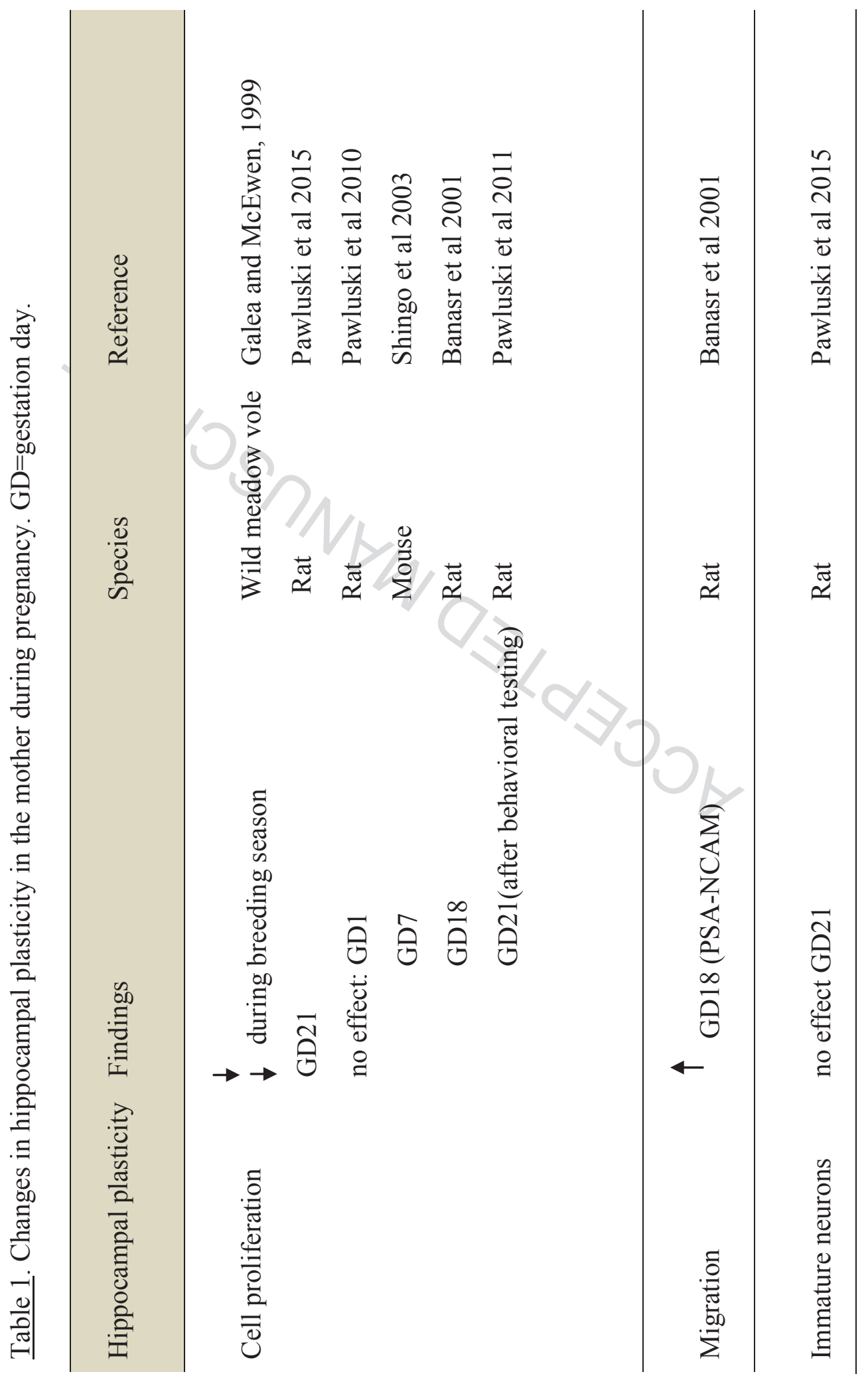




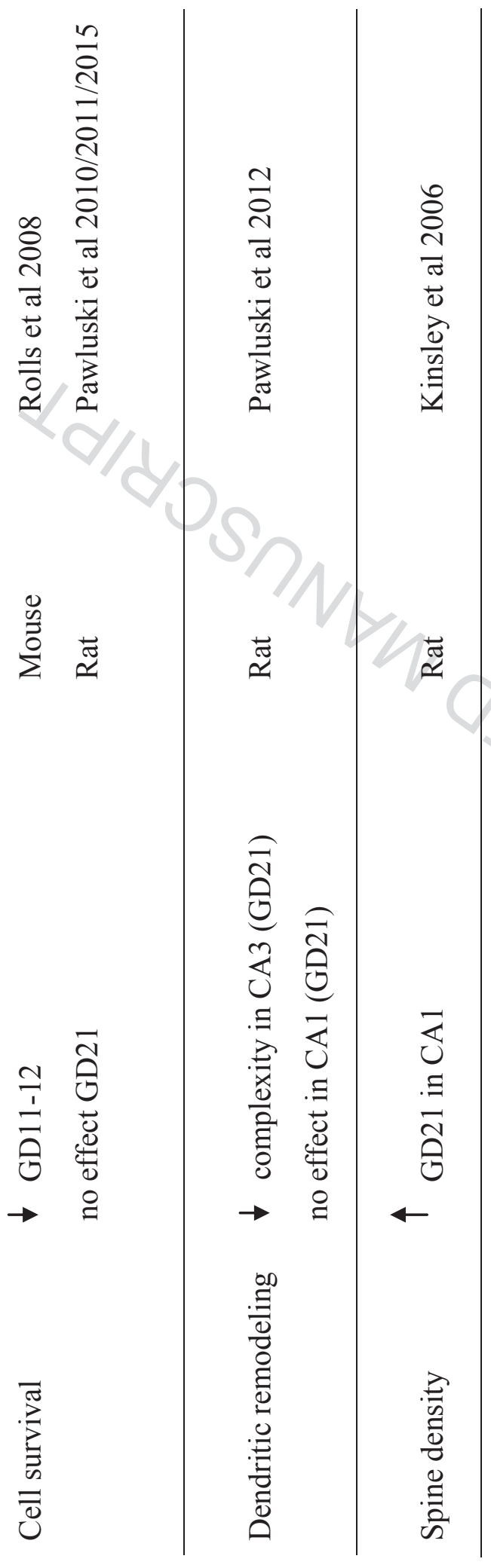




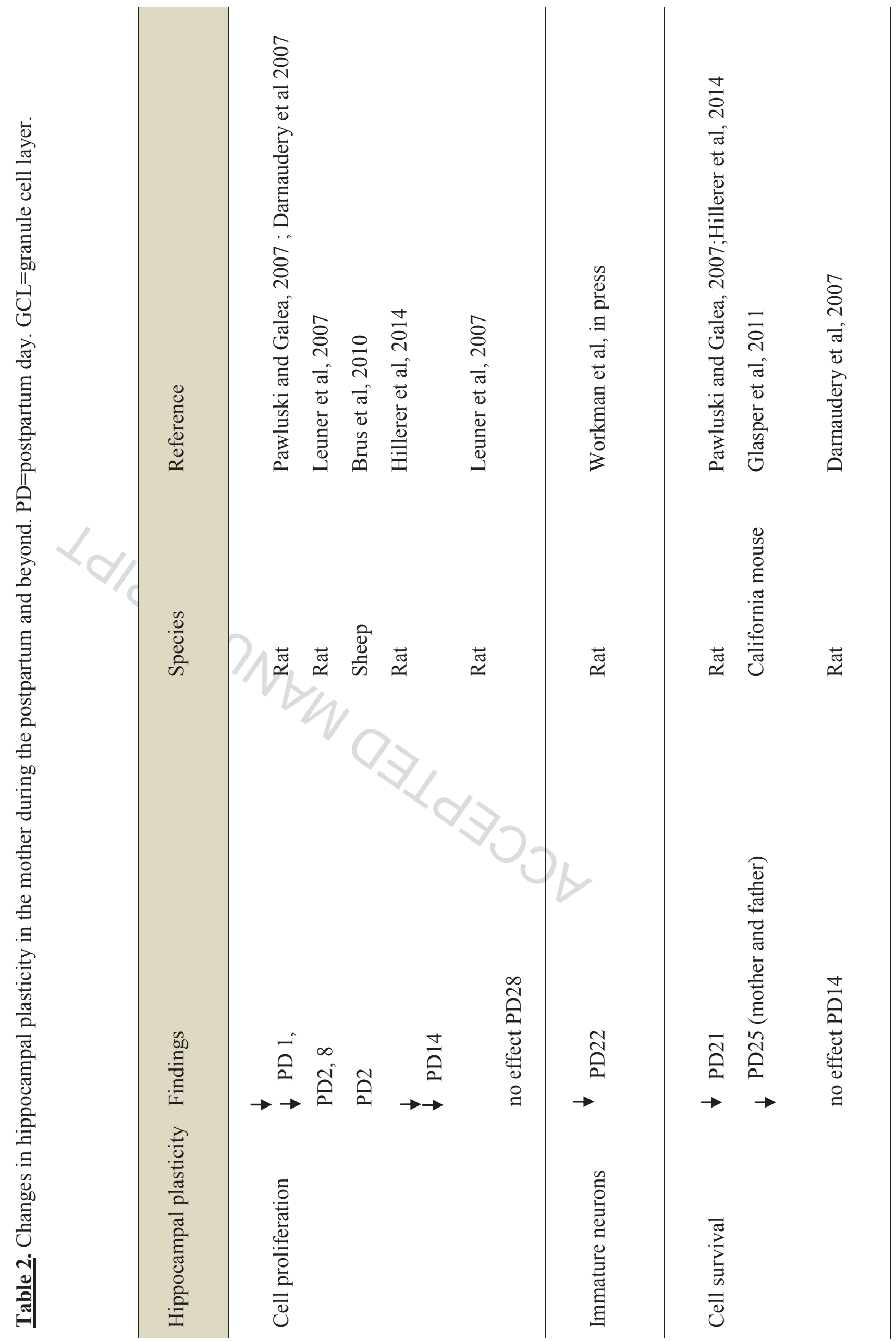




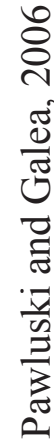

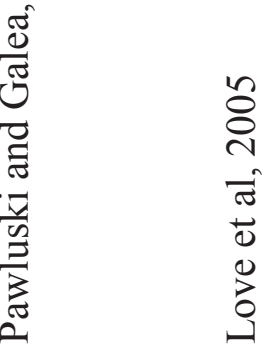

ஓे 응

๖ ญ

元 寻

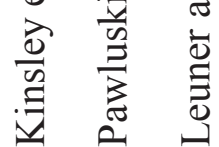

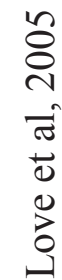

華

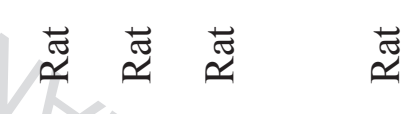

吉

芩

त. ปู

远䓃

$\exists \stackrel{\overrightarrow{0}}{0}$

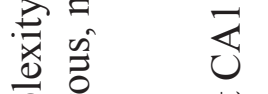

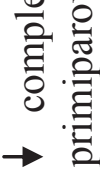

茫

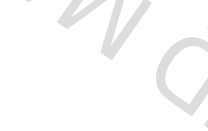

ฝิ

:

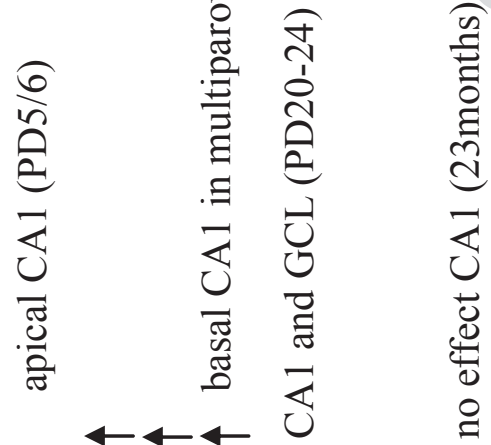

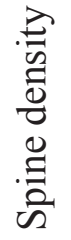




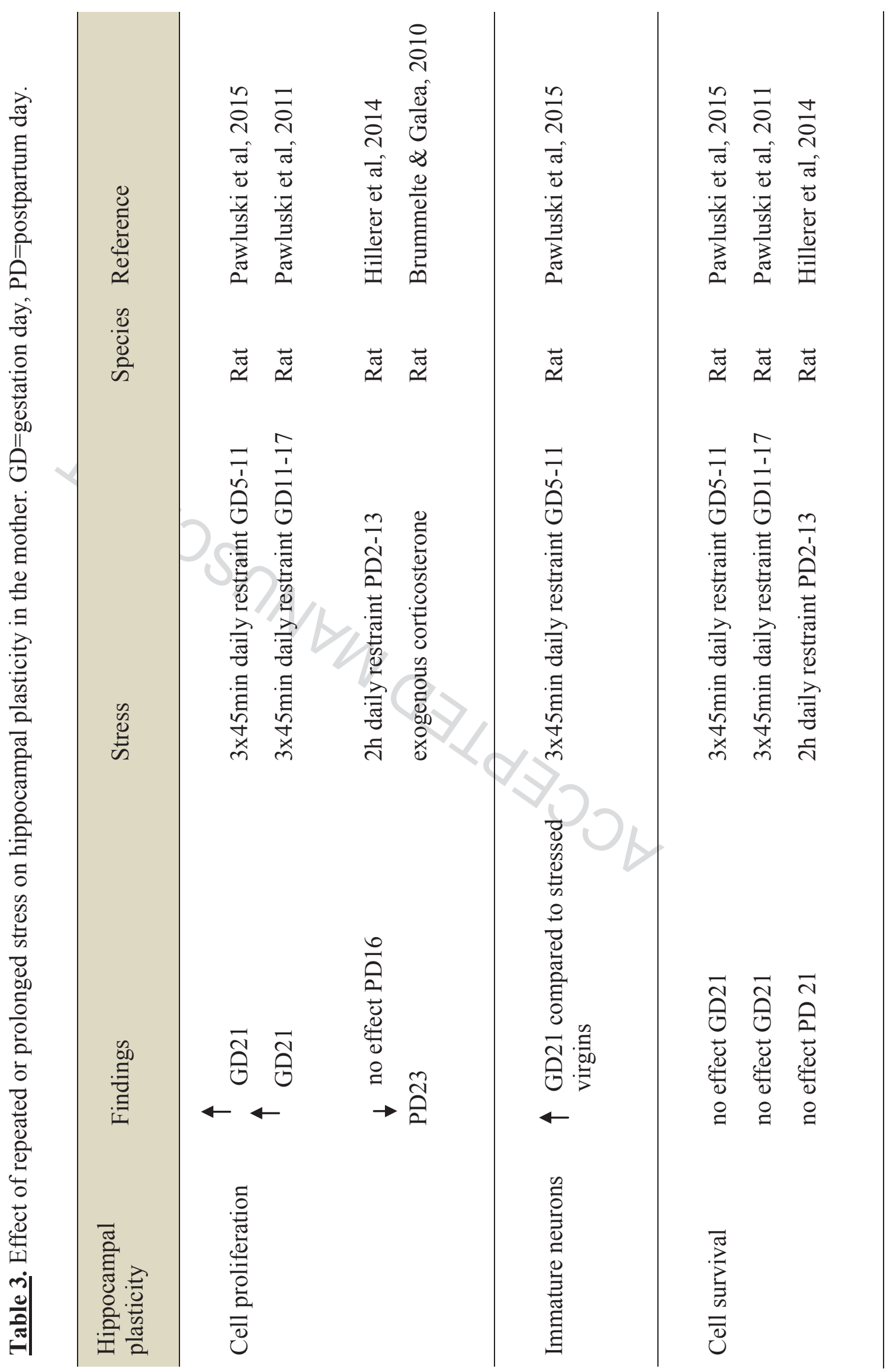




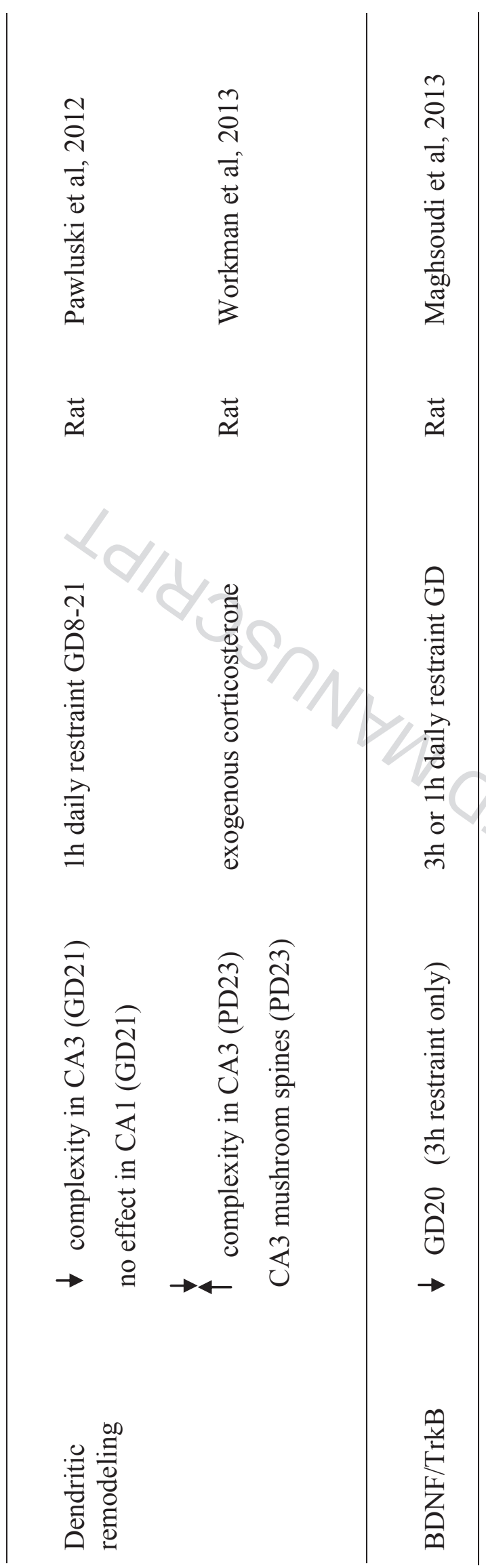


Highlights

- The female brain has an inherent plasticity expressed during reproduction

- There is significant plasticity in the maternal hippocampus

- Hippocampal plasticity in the mother is related to cognition

- Repeated stress can alter remodeling of the maternal brain 